\title{
LA DESPROPORCIÓN DEL TEST DE PROPORCIONALIDAD: ASPECTOS PROBLEMÁTICOS EN SU FORMULACIÓN Y APLICACIÓN
}

\author{
THE DISPROPORTION OF PROPORTIONALITY: SOME PROBLEMATIC \\ ASPECTS IN ITS CONCEPTUAL DEVELOPMENT AND APPLICATION
}

\author{
Ignacio Covarrubias Cuevas*
}

\begin{abstract}
RESUMEN: El presente trabajo plantea cuatro objeciones a la formulación teórica del test de proporcionalidad, advirtiendo los nocivos efectos que su aplicación habitual trae aparejada para la tutela de los derechos fundamentales en caso de emplearse la noción consecuencialista del aludido test. Rescata al mismo tiempo una versión no utilitarista de la proporcionalidad bajo una concepción que permita conciliar la satisfacción del interés público con el pleno respeto a los derechos absolutos o al contenido inviolable de estos. De paso, el artículo critica algunas de las premisas de Robert Alexy sobre los derechos. La conclusión es que el test de proporcionalidad no sirve para todos los casos y que en aquellos en que puede brindar un buen servicio debe operar bajo ciertos resguardos en pos de los derechos fundamentales.
\end{abstract}

Palabras clave: Test de proporcionalidad, balanceo optimizador, contenido inviolable de los derechos, derechos absolutos.

ABSTRACT: This work raises four objections to the theoretical formulation of the test of proportionality, warning the harmful effects that its usual application brings about for the guardianship of the fundamental rights in case that the consequentialist version of the alluded test is used. A non-utilitarian kind of proportionality is rescued and it is suggested, likewise, a conception that should allow to harmonize the satisfaction of the public interest with full respect to the absolute rights or to the inviolable content of these. Meanwhile, the article criticizes several of Robert Alexy's premises on rights. The conclusion is that the test of proportionality does not serve for all the cases and that in those in which it can offer a good service it must operate under certain securities in pursuit of the fundamental rights.

Key words: Proportionality test, optimising balancing, core of rights, absolute rights.

\section{OBJETO DEL TRABAJO}

El presente artículo persigue evidenciar algunos rasgos detectados a partir de la formulación teórica del denominado test de proporcionalidad como estándar de limitación de los derechos fundamentales. Se trata de un análisis primordialmente teórico que persigue advertir, por una parte, algunos efectos coherentes con los presupuestos del aludido test

\footnotetext{
* Profesor de Derecho Constitucional y Director del Centro Justicia Constitucional, Universidad del Desarrollo. Doctor en Derecho, Universidad de los Andes.

Este artículo forma parte del Proyecto de Investigación financiado por la Dirección de Investigación de la referida casa de estudios, titulado "El principio de proporcionalidad en la jurisprudencia del Tribunal Constitucional Chileno” y que se encuentra actualmente en ejecución. Se agradecen los comentarios del profesor de Derecho Constitucional de esta Facultad, Sergio Verdugo Ramírez.
} 
y, por la otra, evidenciar la brecha existente entre algunas de las promesas ofrecidas por el referido estándar de adjudicación y su aplicación concreta, lo cual exige ilustrar dichas falencias con algunos ejemplos en que la proporcionalidad es aplicada o, al menos, invocada.

La hipótesis central apunta a afirmar que habida consideración de una serie de factores -estructura, finalidad y contexto histórico- del aludido test, los derechos fundamentales quedan en buena medida expuestos a un cálculo utilitarista que contribuye a que terminen prevaleciendo los objetivos estatales, invocados por el Estado, a costa del sacrificio de los derechos fundamentales.

Con todo, en el desarrollo del texto se sugieren, aunque sea tangencialmente, algunos resguardos que en el contexto de una de las versiones no consecuencialistas del referido test permitan compatibilizar su empleo para la promoción del bien común con el pleno resguardo al contenido indisponible de los derechos fundamentales. El balance conclusivo es que el test de proporcionalidad no sirve para todos los casos y que en aquellos en que puede brindar un buen servicio debe operar bajo ciertos resguardos en pos de los derechos fundamentales.

Cabe prevenir, finalmente, que este trabajo se referirá preferentemente a las relaciones "verticales" (autoridad-particulares) a las que se aplica el estándar de proporcionalidad y no a las "horizontales" (particular-particular) que también pueden quedar vinculadas por dicho criterio.

\section{EL TEST DE PROPORCIONALIDAD}

\subsection{Aproximación histórica y algunos elementos definitorios de LA PROPORCIONALIDAD}

Aunque las proporcionalidad tiene raíces en los albores del derecho romano ${ }^{1}$, y como exigencia de justicia posee diversas manifestaciones jurídicas ${ }^{2}$, los primeros antecedentes explícitos de este principio en el derecho continental pueden encontrarse en la doctrina penal -concretamente Becaría- en cuanto demandaba la existencia de "una proporción entre los delitos y las penas" 3 .

Se ha dicho que los primeros lineamientos embrionarios del test de proporcionalidad, que pretenden proveer de fundamento estable a las intervenciones del poder de policía en la esfera de la libertad individual, en la Alemania del siglo XVIII, surgen en el Derecho prusiano, de parte de Carl Svarez, quien afirmaba que “(...) el Estado solo tiene derecho a restringir la libertad de los particulares en cuanto sea necesario para poder hacer compatibles la libertad y seguridad". Agregaba finalmente: "[l]os daños que mediante la restricción de la libertad deben ser evitados, deben tener una importancia mucho mayor que la desventaja que la

\footnotetext{
${ }^{1} \mathrm{Al}$ respecto, véase Casinos Mora (2005) pp. 185-204.

${ }^{2}$ Aparte del derecho penal, en que la gravedad de la sanción se supone ha de ser proporcional a las gravedad del delito, en el derecho internacional, el uso de la fuerza como respuesta al agresor injusto debe ser proporcionado, para proteger la población civil. Hoy también suele invocarse la proporcionalidad (terapéutica) para rechazar métodos de tratamiento médico que sean excesivos. Una valoración sobre algunos aspectos positivos y negativos en este ámbito, véase Vivanco (2009) pp. 399-440.

${ }^{3}$ Becaría (1982) p. 138. Su doctrina fue recogida por la Declaración de Derechos del Hombre y del Ciudadano, que en su artículo $8^{\circ}$ expresaba: "La ley no debe establecer otras penas que las estricta y evidentemente necesarias".
} 
comunidad y los particulares sufren a causa de una restricción semejante" ${ }^{4}$. Con estas expresiones el jurista alemán adelantaba los elementos definitorios de lo que luego se denominaría el subprincipio de proporcionalidad en sentido estricto.

La noción primigenia ha sido adecuadamente explicada en el contexto de la concepción contractualista, catalizada tras el estallido de la Revolución Francesa, según la cual las intervenciones estatales en la esfera de la libertad individual solo debían ser excepcionales y limitarse a los casos necesarios y con la intensidad indispensable para satisfacer las exigencias impuestas por el interés general ${ }^{5}$. Bajo el influjo de la teoría de los derechos individuales confrontados al poder del Estado, cualquier restricción de este en la esfera de la libertad no solo debía justificarse sino también dichas intervenciones debían ser proporcionadas.

Para sostener el crecimiento de un Estado liberal que asume como función básica la conservación de la paz y de la seguridad, surge el brazo del Derecho Administrativo, llamado entonces a disciplinar jurídicamente la intervención pública ${ }^{6}$. A partir de dicho momento los tribunales de justicia, en sede administrativa u ordinaria, ejercerían un incipiente control sobre algunos elementos que a la postre pasarían a formar parte de los subprincipios de la proporcionalidad, a saber, la adecuación de los medios a la finalidad perseguida por la regulación estatal, verificando además si las restricciones adoptadas superaban lo estrictamente necesario de conformidad a las exigencias demandadas por el objetivo público (finalidad legitima $)^{7}$.

Mientras lo señalado tenía lugar en Europa continental -fundamentalmente en Prusia y Alemania- un fenómeno de alcances más restringidos aunque bastante similar en su operatividad y finalidad ocurría en el Derecho inglés y norteamericano, donde se advertía la necesidad de incorporar límites inherentes a la intervención pública mediante el empleo de la razonabilidad ${ }^{8}$ (inglesa) y de la alternativa menos restrictiva ${ }^{9}$ (norteamericana), muy similar al actual test de proporcionalidad, en buena medida durante la evolución del "substantive due process"10. Con posterioridad, el Tribunal Supremo de Estados Unidos ha venido aplicando un estándar en un aspecto similar -el strict scrutiny test ${ }^{11}$ - aunque más

\footnotetext{
${ }^{4}$ Glottlieb (1791) cita tomada de Schneider (1976) p. 393, y Bernal (2003) pp. 40-41.

5 JellineK (2000) pp. 205 y ss. En materia penal, esta doctrina había sido ya recogida por la Declaración de Derechos del Hombre y del Ciudadano, que en su artículo $8^{\circ}$ expresaba: "La ley no debe establecer otras penas que las estricta y evidentemente necesarias".

${ }^{6}$ Barnes (1998) p. 24.

7 Barnes (1998) p. 24.

${ }^{8}$ Cianciardo (2000) pp. 290-296.

${ }^{9}$ La siguiente opinión del Tribunal Supremo norteamericano es ilustrativa de lo señalado, en Lawton v. Steele (1894): "Para justificar la intervención de la autoridad del Estado en nombre del público, debe aparecer (...) que los medios sean razonablemente necesarios para el cumplimiento del propósito, y no indebidamente opresivo respecto de los individuos. El legislador no puede (...) imponer restricciones inusuales e innecesarias respecto de actividades lícitas. En otras palabras, su decisión acerca de lo que constituye un adecuado ejercicio de su poder de policía si bien no es decisivo ni definitivo, está, sin embargo, sujeto a la supervisión de este tribunal', cit. por Bastress (1974) p. 976. ${ }^{10}$ Bastress (1998) p. 974, y Sullivan, Thomas F. y Frase, Richard S. (2009) pp. 54-58.

11 "También están presentes en el tradicional test de proporcionalidad. Primero, el Tribunal ha de determinar si la acción del gobierno vulnera un derecho fundamental o discrimina contra alguna persona. Si asi ocurre, el Tribunal debe invalidar la acción gubernamental, a menos que sea necesaria para la obtención de un fin [público] imperioso. El fin gubernamental involucrado debe ser suficientemente relevante como para justificar una discriminación o la
} 
exigente que la proporcionalidad ${ }^{12}$. En cambio, el Derecho británico ha incorporado definitivamente el test de proporcionalidad con ocasión de la aprobación del Human Rights Act (1998) por parte del Reino Unido ${ }^{13}$.

\subsection{Formulación generalmente indisputada EN Europa: el CRiterio de OPTIMIZACIÓN DE INTERESES}

En un sentido amplio, la doctrina de la proporcionalidad se conoce como el conjunto de exigencias o tests utilizados para verificar si la restricción a uno o más derechos fundamentales es justificada. Desde esta perspectiva, si una limitación de derechos es proporcionada, es justificable. Si no es proporcionada, no lo es ${ }^{14}$.

La formulación bastante indisputada ${ }^{15}$ con la que actualmente se conoce la proporcionalidad se aviene mucho más con la expresión test que con el término principio del mismo apellido (nos referiremos indistintamente al "test" o "principio" de proporcionalidad). Mucho menos se asemeja a la originaria prohibición por exceso, atendida la estructura copulativamente articulada de sub principios que configuran aquello que se denomina bajo el aludido método. En concreto, y sin perjuicio de las diferencias que perfilan sus distintas aproximaciones, la modalidad con que suele conocerse es bajo la fórmula de tres o cuatro subprincipios ${ }^{16}$.

Así, el test de proporcionalidad surge habitualmente como un conjunto escalonado de tres subprincipios -idoneidad, necesidad y proporcionalidad en sentido estricto- cada uno de los cuales expresa una exigencia que toda injerencia de autoridad estatal en los derechos fundamentales debe satisfacer ${ }^{17}$. Estos requisitos pueden explicarse del siguiente modo: la adecuación o idoneidad persigue verificar que el o los medios adoptados por la autoridad sean aptos para alcanzar un fin constitucionalmente legítimo. Ya veremos que este subprincipio expresa dos requisitos diversos: la idoneidad del medio y la licitud del fin.

La segunda exigencia, la necesidad supone que la medida no restrinja el derecho más allá de lo estrictamente necesario para la satisfacción del fin invocado. Dicho de otro modo,

intervención en la autonomía individual. El resultado es que la acción del gobierno es invalidada si la Corte es capaz de encontrar un instrumento alternativo menos restrictivo aunque igualmente efectivo". (SUllivan y Frase, 2009, p. 54). En sentido similar, Stone y Mathews (2008) pp. 78-79.

${ }^{12}$ Cabe señalar por vía ejemplar, un par de casos contemporáneos en que se ha utilizado el referido criterio, bajo diversas expresiones: "the less drastic means", United States v. Robel (1967) y "necessity", en Dunn v. Blumstein (1972).

${ }^{13}$ Arancibia (2011) pp. 133-215, En cuya tesis sostiene el avance que supone el test de proporcionalidad en el contexto tradicional inglés de una "deferencia razonada" frente a las medidas regulatorias que en el campo económico adopta la autoridad estatal.

${ }^{14}$ Rivers (2006) p. 174.

15 ZúNiga (2010) pp. 249-272 y Díaz (2011) pp. 167-206, en interesantes artículos publicados en nuestro país, a favor del test de proporcionalidad, lo asumen -como si no hubiera otro- bajo su noción optimizadora.

${ }^{16}$ Por ejemplo, para el Tribunal Europeo de Derechos Humanos, las injerencias estatales en los derechos fundamentales compatibles con el Convenio europeo, deben ser (a) previstas en la ley, (b) necesarios en una sociedad democrática para conseguir un fin legítimo y (c) proporcional con relación al fin legítimo perseguido. Véase FERNÁNdez (2009) pp. 216-221.

17 En la doctrina alemana contemporánea: Alexy (2002). En España: Barnes (1994) pp. 500-501, Medina (1997) pp. 120, Perello Domenech Isabel (1997) pp. 70 y ss. y Bernal (2003) pp. 36-37. En Chile: Nogueira (2010) pp. 353-403, Zúñiga (2010) 249-272. y, Díaz (2011) pp. 167-206. En Inglaterra: Craig (2003) p. 622. En EEUU: Sullivan y Thomas. (2009) pp. 53-66 y Stone y Mathews (2009) pp. 53-66. 
la necesidad consiste en la aplicación del "medio menos restrictivo", según el criterio norteamericano ${ }^{18}$. Cumplidos los pasos precedentes, el tercer requisito -la proporcionalidad en estricto sentido- supone el ejercicio de balancear o ponderar los beneficios de la medida impuesta versus los costos de haber incurrido en la vulneración de un derecho fundamental para concluir en qué lado se produce el mayor bien.

De este modo, si la medida gubernamental adoptada fracasa en el cumplimiento de estas tres o cuatro exigencias, se entiende que trasgrede el derecho fundamental intervenido, motivo por el cual dicho acto legislativo o administrativo debe ser declarado inconstitucional.

La formulación explicada, prevaleciente en Europa, arroja un elemento común subyacente a la noción del principio de proporcionalidad: que si bien este nace como un instrumento de defensa de la libertad individual frente al poder, su devenir dependerá en un grado no menor de la relevancia de los objetivos que se pretende alcanzar, conforme a un test utilitarista con los derechos fundamentales. Así, estos quedarán en buena medida a expensas de la satisfacción de un fin público cumpliéndose que sea el resto de los presupuestos del test de proporcionalidad, entre los cuales no se encuentra el respeto al contenido medular de los derechos fundamentales ni tampoco la dignidad de la persona.

Un partidario de esta visión -que denomina "concepción de optimización de la proporcionalidad" ("optimising conception") - afirma que esta noción "observa la proporcionalidad como una aproximación estructurada para balancear derechos fundamentales con otros derechos o intereses del mejor modo posible", a diferencia del concepto predominante en Gran Bretaña, que critica, al considerar la proporcionalidad "como un conjunto de tests que garantizan la protección judicial frente a la interferencia en los derechos" 19 . Sobre esta nos referiremos enseguida.

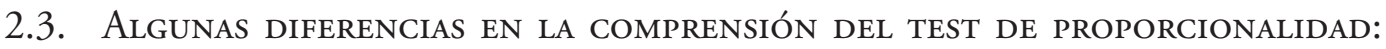 EL CONCEPTO NO CONSECUENCIALISTA ${ }^{20}$}

Sin perjuicio de algunas diferencias existentes sobre las exigencias del test en ciertas latitudes ${ }^{21}$, la noción hasta aquí expuesta es la que concita el sustento mayoritario -casi absoluto en el derecho continental europeo- acerca de la noción y estructura del test de proporcionalidad. Con todo, algunas divergencias no menores se advierten en la comprensión de este estándar, principalmente de parte de algunos países de la tradición jurídica anglosajona. Nos referiremos a las divergencias en cuanto al primer y último subprincipios para

\footnotetext{
18 Sullivan y Frase (2009) y Stone (2009).

${ }^{19}$ Rivers (2006) p. 176.

20 Para el consecuencialismo no hay bienes o derechos cuya trasgresión sería intrínsecamente mala, ya que para saberlo habría que calcular o ponderar los efectos buenos y malos que de tales acciones se seguirían, en cada caso. Una obra cuyo título no puede ser más representativo entre los partidarios del consecuencialismo es la de McCormick (1978), titulada: Doing Evil to Achieve Good. Moral Choice in Conflict Situations, pp. 7-53. Un típico ejemplo consecuencialista es fundar la licitud de la pena de muerte fundamentalmente en estudios que demuestren que su establecimiento se traduciría en un beneficio social, por ejemplo, una notable disminución de la tasa de homicidios. Lo admite Posner (1979) pp. 103-140. El mismo artículo traducido al español en: http://www.cepchile.cl/dms/lang_1/doc_1088.html

${ }^{21}$ A modo ejemplar, Conesa (2010) pp. 351-357, en que trata sobre la "tropicalización" del principio de proporcionalidad -particularmente en el ámbito de la igualdad- en Colombia y México.
} 
finalizar mostrando cómo en el Reino Unido ha prevalecido una noción un tanto alternativa a la predominante en Europa.

En cuanto al primer subprincipio, determinados países -Reino Unido ${ }^{22}$, Canadá ${ }^{23}$, Sudáfrica ${ }^{24}$, entre otros- ilustran que los dos requisitos contenidos en el primer paso (medio adecuado a un fin legítimo) pasan a constituir dos exigencias diversas: la primera, consistente en que la decisión adoptada persiga un fin constitucionalmente legítimo o un objetivo suficientemente importante. La segunda, que dicha medida estatal sea idónea para satisfacer la finalidad pública. En el primer paso, el subprincipio se denomina de Legitimidad o de Fin constitucionalmente legítimo y en el segundo caso no estamos sino ante el ya señalado subprincipio de adecuación o idoneidad.

En algunos países, el requisito de legitimidad del fin se entiende implícitamente satisfecho al cumplirse con la adecuación o simplemente no es tomado en consideración ${ }^{25}$. En ambas hipótesis, el resultado es el mismo: la irrelevancia de someter a un escrutinio constitucional el fin público invocado por la autoridad. Así, la aludida refundación de dos exigencias en una sola tiende a ir en un evidente detrimento del examen acerca de la licitud o relevancia de la finalidad u objetivo público invocado por la autoridad al adoptar la medida restrictiva de derechos, llegándose en muchos casos al extremos de omitirse derechamente su observancia como uno de los subprincipios exigidos dentro del test de proporcionalidad ${ }^{26}$.

La segunda diferencia, no tan manifiesta ni extendida como la precedentemente expuesta, se refiere la noción del último subprincipio, esto es, a la proporcionalidad en sentido estricto. Como ya se anotó, para la gran mayoría, la aludida exigencia supone un ineludible balanceo de costo-beneficio entre la medida limitativa de derechos y el fin público invocado. Para otros, en cambio, dicho requisito se cumple en la medida que el acto restrictivo adoptado por la autoridad no tenga un resultado que sea excesivo ni desproporcionado en los derechos afectados, entendiendo por esto que no los prive de su contenido medular ni tampoco los desconozca.

\footnotetext{
${ }^{22}$ A partir de De Freitas v. Permanent Secretary of Ministry of Agriculture, Fisheries, Land and Housing (1999), los tribunales ingleses se preguntan si la medida cuestionada persigue un "sufficiently important objective", p. 80. Otros casos en que esto ha ocurrido, por vía ejemplar: $R$. (Daly) v. Secretary of State for the Home Department (2001) y, A. v. Secretary of State for the Home Department (2005), aunque estos dos últimos modifiquen el test en otros aspectos.

${ }^{23}$ En Regina v. Oakes (1986) el primer caso que formula en propiedad el test, la C. Suprema distingue la idoneidad ("la medida adoptada debe estar cuidadosamente diseñada para alcanzar el objetivo", 139) de la legitimidad del fin ("de importancia suficiente como para justificar pasar por encima de un derecho constitucionalmente protegido”, 138).

${ }^{24}$ La Constitución sudafricana de 1996 prevé expresamente el test: “Los derechos pueden ser limitados (...) considerando todos los factores relevantes, incluyendo la naturaleza del derecho; la importancia del objeto de la limitación; la naturaleza y extensión de la limitación; la relación entre la limitación y su finalidad; y los medios menos restrictivos para alcanzar la finalidad' (art. 36.1).

${ }^{25}$ En España: Pereira (2004) pp. 1047-1054. En Chile, García (2011) pp. 110-116 y Covarrubias (2011) pp. 422-425. Este autor identifica dos casos en que excepcionalmente el TC chileno no da por sentado el interés público invocado por la autoridad en un acto limitativo de derechos: uno, en Decreto de Urbanismo y Construcción, rol No 370-2003, c. 31 ${ }^{\circ}$; el otro en TVN con Consejo para la Transparencia, rol 1.800-2010, c. $25^{\circ}$.

${ }^{26}$ Nogueira (2010) p. 356, indirectamente ha llamado la atención sobre la omisión señalada al afirmar que "[l]os derechos fundamentales (...) solo pueden ser limitados en virtud de un bien constitucionalmente protegido o de relevancia constitucional, no pudiendo ser limitados por bienes o intereses infra constitucionales".
} 
Esta excepcional aproximación acerca del último requisito del test es posible encontrarla en la legislación y fallos ingleses como asimismo en algunos autores de dicha tradición, luego que el Reino Unido adoptara la proporcionalidad. En término amplios, dicho paso se encuentra resumido en el principio legislativo que observa a la proporcionalidad como un límite expreso a la potestad regulatoria, de modo que "el efecto de las disposiciones regulatorias debe ser proporcionado al fin público y producir un justo equilibrio entre el interés público y los derechos de cualquier persona perjudicialmente afectada" 27

Más aún, cuando se inauguró la aplicación jurisprudencial del test en Gran Bretaña -en De Freitas (1999) - se sentó un estándar de tres exigencias, la última de las cuales se preguntaba "si las medidas adoptadas son lo estrictamente necesarias para lograr ese objetivo [suficientemente importante]" 28 . Por el lado de la doctrina, el citado criterio judicial resulta similar a aquel adoptado por Wade y Forsyth, quienes estiman que este estándar "ordena que las medidas administrativas no sean más drásticas que lo estrictamente necesario para obtener el resultado querido"29. En una línea análoga, Lester y Pannick interpretan el subprincipio de necesidad como equivalente a una condición de "justo equilibrio" (fair balance) ${ }^{30}$, mientras Clayton y Tomlinson lo asumen como una exigencia de que tiene por objeto impedir "cargas o daños excesivos" (excessive burdens or harms) ${ }^{31}$.

No obstante los matices revelados entre las formulaciones esbozadas -unas más proclives a privilegiar el resultado antes que la protección de los derechos- en todas ellas subyace un denominador común: primero, que simplemente se omite o excluye deliberadamente el subprincipio de balanceo o proporcionalidad en sentido estricto, la aproximación más utilitarista del test, observada predominantemente en Europa y, en segundo término, según la perspectiva expuesta, el estándar no consiste en optimizar costos y beneficios, situando a los derechos y a los intereses invocados por el Estado en lados opuestos de la balanza, sino que en lograr la más eficiente búsqueda de objetivos relevantes de política pública, sin necesariamente llegar a sacrificar a los derechos en juego.

\section{LA PARADOJA DE LA PROPORCIONALIDAD: PARECE CONCEBIDO PARA HACER PREVALECER EL FIN REGULATORIO POR SOBRE LA PROTECCIÓN AL DERECHO FUNDAMENTAL}

Como ya lo adelantáramos, la actual estructura del test contribuye a que los derechos queden en buena medida sujetos a un cálculo donde muchas veces prevalece la supuesta primacía de los objetivos estatales que legítimamente se pretenden alcanzar a costa del sacrificio de los derechos fundamentales. En este apartado señalaremos de qué manera la estructura, finalidad y contexto histórico contribuyen al resultado señalado. Para finalizar, haremos referencia a algunos casos en que lo señalado se observa en la práctica.

\footnotetext{
${ }^{27}$ Regulatory Reform Act 2006 (UK), section 3 (2). (La cursiva es propia).

${ }^{28}$ De Freitas v. Permanent Secretary of Ministry of Agriculture, Fisheries, Land and Housing (1999).

${ }^{29}$ Wade y Forsyth (2004) p. 366.

${ }^{30}$ Lester y Pannick (2004) p. 89.

${ }^{31}$ Clayton y Tomlinson (2000) p. 298.
} 
Ya hemos advertido que una de las divergencias acerca del test de proporcionalidad dice relación con aquellos que sustentan una noción más afín al balanceo, de raigambre Europea, versus otra que más bien excluye el análisis de optimización de costo-beneficio, en Gran Bretaña. Mientras la primera subraya la necesidad de que el gravamen ocasionado (en el derecho fundamental) por la intervención estatal se vea compensado por la envergadura de los fines alcanzados o por alcanzarse a través de la medida pública adoptada ${ }^{32}$, la noción menos utilitarista enfatiza que la intensidad de las medidas restrictivas no vayan más allá de lo estrictamente necesario para lograr el legítimo fin público ${ }^{33}$.

No obstante las aludidas divergencias conceptuales existentes entre los exponentes de una aproximación utilitarista y aquellos que eliminan del test el lenguaje del balanceo, hay entre ellos un amplio punto de convergencia y consiste en que debe privilegiarse la satisfacción de la medida gubernamental presupuestada por sobre el respeto al contenido del derecho intervenido. En ello coinciden europeos e ingleses, con algunas excepciones entre los últimos ${ }^{34}$. Si bien este principio eleva formalmente los requisitos para intervenir un derecho fundamental como consecuencia de la definición y/o aplicación de potestades regulatorias que busquen satisfacer una necesidad pública, suele pasar bastante inadvertido que este instrumento se encuentra concebido por una lógica -instrumental, finalista, histórica- que contribuye a justificar en la práctica que el objetivo constitucionalmente invocado como legítimo termine habitualmente llevando al despeñadero al derecho intervenido.

En efecto, desde el punto de vista estructural dos de los cuatro subprincipios apuntan a imponer exigencias a la medida adoptada por la autoridad. Sin embargo, ocurre que generalmente el requisito de un fin constitucional legitimo o relevante se entiende incorporado en la idoneidad (en cuyo caso el fin se entiende implícitamente satisfecho si se cumple aquella) o es derechamente omitido del análisis ${ }^{35}$. Cualquiera sea el caso, los dos primeros requisitos raramente son objeto de un real o efectivo escrutinio, con lo cual la revisión del test suele focalizarse en las dos restantes exigencias aunque veremos que la falencia respecto del primero puede incidir directamente en un déficit analítico sobre el último, la proporcionalidad en estricto sentido, en su versión optimizadora.

El tercer requisito -el subprincipio de necesidad o de medida menos restrictiva- supone que la medida de intervención en el derecho afectado no lo limite más allá de lo estrictamente necesario para la satisfacción del fin invocado o que el acto adoptado sea el menos restrictivo de entre todas las alternativas disponibles. Si bien puede aparecer que esta exigencia de la proporcionalidad es la única que directamente persigue brindar protección al derecho intervenido, ella más bien mira a la satisfacción del objetivo invocado como legítimo antes que a asegurar el resguardo al derecho fundamental.

Lo afirmado se devela de este modo: la necesidad exige que la intervención sufrida por el derecho sea la mínima en consideración al fin buscado. De esta forma, se cumple lo

\footnotetext{
${ }^{32}$ A modo ilustrativo: Alexy (2002) p. 50 y (2003) pp. 435-436 y Barnes (1998) p. 23.

33 A modo ejemplar: Wade y Forsyth (2004) y De LA Riva (2004).

${ }^{34}$ Elliott (2001) p. 173.

35 En tal sentido: España, Pereira (2004) pp. 1047-1054. En Chile, Covarrubias (2011) pp. 422-425. Contra, Grimm (2007) p. 388, quien revela que la Corte Suprema Canadiense exige como primer requisito que la finalidad de la ley sea "de suficiente relevancia" como para pasar por encima de un derecho fundamental.
} 
dispuesto por este subprincipio si la afectación en el derecho fundamental -aunque excesiva, desorbitada o desproporcionada- permite satisfacer el fin público. Pongámoslo así: si la exigencia de intervención mínima es con miras a la obtención del fin buscado no importa cuán lesiva llegue a ser la injerencia de la autoridad en el derecho con tal que dicha intensidad haya sido la mínima para la prosecución del objetivo público delineado.

Se dirá que lo afirmado es admisible en una aislada consideración, ceteris paribus, de la aludida exigencia y que para evitar el referido exceso se ha previsto pasar bajo el examen del último requisito del test -la proporcionalidad en sentido estricto- en cuanto este tiene por objeto impedir "cargas o daños excesivos" (excessive burdens or harms) ${ }^{36}$ o lograr el resultado equivalente a una condición de "justo equilibrio" (fair balance) entre los intereses en juego ${ }^{37}$. Desde esta vereda parecería sensato concluir que bajo un efectivo examen de proporcionalidad se evitaría legitimar la adopción de una medida desproporcionada, entendiendo por esta aquella que sacrificara parcial o completamente a un derecho fundamental en manos del interés público invocado por el Estado.

Este resultado, sin embargo, solo sería coherente en el específico contexto de aquella noción no utilitarista del test, ya expuesta, mientras que bajo el influjo de la mayoría de la realidad doctrinal y práctica europea el análisis de costo-beneficio difícilmente arribaría a la conclusión de que la medida invocada por el Gobierno (asociada a un supuesto interés público) provee de menores beneficios que aquellos representados por un derecho (muchas veces asociado a un supuesto interés particular): puesto en estos términos, entre el interés público y uno privado no habría cómo dudar dónde inclinar la balanza de la proporcionalidad en sentido estricto.

En fin, si es indispensable (necesario) el parcial o total sacrificio de un derecho para lograr el objetivo público, ello se condice con la lógica del estándar de proporcionalidad, quedando reservado para el último paso del test el eventual resguardo del derecho afectado. Digo, eventualmente, toda vez que se ha visto que la tutela efectiva de la libertad ha quedado, en su gran mayoría, sujeta a un balanceo de intereses en que los derechos llevan todas las de perder, contrariamente a lo que Svarez (1746-98) sostuvo al formular por vez primera la proporcionalidad.

Afirmó, al respecto, que "[s]olo la obtención de un bien mayor para todos justifica que el Estado exija de una persona el sacrificio de un bien menor. En la medida que la diferencia de peso [entre ambos bienes] no sea obvia, la libertad es la que debe prevalecer (...)"38. Esta inclinación a favor de los derechos fundamentales ha cedido en pos de una supuesta prevalencia del bien invocado por el Gobierno sobre el respeto a los derechos fundamentales, salvo la ya mencionada excepcional interpretación sobre el último subprincipio.

Al encontrarse prácticamente la totalidad del test de proporcionalidad condicionado a admitir la legitimidad de la finalidad invocada por el Gobierno, dicho estándar aparece como instrumentalmente estructurado para favorecer a la obtención del referido objeto. Sin embargo, una explicación únicamente formal resulta insuficiente a la hora de explicar los

\footnotetext{
${ }^{36}$ Clayton y Tomlinson (2000) p. 298.

${ }^{37}$ Lester y Pannick (2004) p. 89.

38 Glottlieb (1906) p. 40, citado por Stone y Mathews (2009) p. 99.
} 
motivos del resultado muchas veces previsible del referido test, esto pues la proporcionalidad no es una herramienta neutral para la obtención de finalidades normativamente contrapuestas $^{39}$. Por el contrario, coincidimos en que este instrumento, en su conjunto, constituye intrinsecamente una exigencia de justificación de la acción estatal ${ }^{40}$.

¿Qué es lo que la proporcionalidad pretende justificar? Desde una perspectiva finalista, la mayoría de la doctrina es conteste en señalar que el propósito de la proporcionalidad es propender a lograr un resultado muy concreto: que el objetivo invocado por la regulación sea satisfecho. A modo ilustrativo, Barnes -uno de los autores de habla hispana más citados en la materia- lo afirma categóricamente: "[l]a razón de ser, pues, de (...) la proporcionalidad reside en la necesidad de legitimar la acción estatal por el fin al que sirve" ${ }^{41}$. En un sentido análogo, Thomas, afirma que este criterio propugna a que se cumpla el objetivo de política pública elegido antes que el fracaso del mismo ${ }^{42}$.

Incluso en Estados Unidos, donde el Tribunal Supremo emplea un test en algo afín a la proporcionalidad aunque bastante más exigente, Sullivan y Frase, señalan que "para sobrevivir a un strict scrutiny la acción del gobierno debe satisfacer un interés público imperioso" 43 , con lo cual se admite que el derecho fundamental puede ser superado por el interés público. No solo el interés invocado (como generalmente ocurre con la proporcionalidad) sino también probado ${ }^{44}$ por la autoridad.

El misma tendencia se sitúa Alexy, quien al explicar la proporcionalidad en estricto sentido expresa que "mientras mayor sea el grado de no satisfacción, o de detrimento, de un principio, mayor debe ser la importancia de satisfacer el otro" ${ }^{45}$, con lo cual admite que la interferencia a un derecho fundamental por parte de una medida legislativa se verá legitimada solo en la medida en que se justifique la relevancia de satisfacer el otro principio en conflicto. Esto, por lo demás, calza plenamente con una de las ideas centrales del autor alemán -y de la mayoría de los promotores del test- en cuanto a que la regulación estatal puede vulnerar un derecho solo en la medida necesaria para cumplir con un objetivo legítimo ${ }^{46}$.

La perspectiva estructural y finalista del estándar expuesto cobra pleno sentido a la luz del contexto histórico en que el referido criterio dio a luz en Europa. No es controversial sostener que la proporcionalidad surge para hacer frente al auge del Estado intervencionista contemporáneo. Emiliou lo confirma hoy en día al señalar que la proporcionalidad constituye "la herramienta más apropiada para controlar la actividad intervencionista del Estado de bienestar" ${ }^{47}$. Y es evidente que en un Estado intervencionista lo más relevante es que el legítimo objetivo de política pública adoptado por el Gobierno se cumpla -con la

\footnotetext{
${ }^{39}$ Una reciente crítica a la supuesta neutralidad del test en: WeBber (2010), pp. 191-194.

${ }^{40}$ Cohen-Eliya y Porat (2011) p. 474.

41 Barnes (1998) p. 23.

42 Thomas (2000) p. 85. Citado por Arancibia (2011) p. 136.

43 Sullivan y Frase (2009) p. 54, criterio este citado de Griswold, v. Connecticut (1965).

${ }^{44}$ En el strict scrutiny test, el Tribunal Supremo ha exigido al Gobierno demostrar que la medida adoptada es "estrictamente adecuada" (narrowly-tailored) para la satisfacción no de cualquier objetivo público invocado por aquel sino de uno "imperioso" (compelling government interest).

${ }^{45}$ Alexy (2002) p. 102.

${ }^{46}$ Alexy (2002) p. 50 y en Alexy (2003) pp. 435-436.

${ }^{47}$ Emiliou (1996) p. 21.
} 
menor restricción a los derechos fundamentales, claro está- pero en la medida en que dicha finalidad se satisfaga. Así ha sido entendido para los primitivos ${ }^{48}$ y contemporáneos ${ }^{49}$ teóricos alemanes de la proporcionalidad.

Con todo, el estándar en cuestión no conduce mediante un ejercicio mecánico a la obtención del fin constitucional invocado por el Estado en la medida restrictiva de derechos fundamentales sino que el conjunto de factores señalados solo favorece o contribuye decisivamente a dicho resultado atendido el contexto, ya descrito, en el que el test de proporcionalidad es concebido y se desenvuelve.

Finalmente, hay algunos ejemplos de la práctica jurisdiccional, comparada como nacional, en que al menos parcialmente, se ha confirmado lo hasta aquí sostenido. Uno de los casos más sensibles resueltos por Tribunales Constitucionales extranjeros son aquellos en que, justificados en el test de proporcionalidad, el derecho a la vida del embrión humano ha terminado por sucumbir ante la política pública sanitaria de promoción de los, así llamados, derechos reproductivos de la mujer ${ }^{50}$, invocados por ella misma o por el Gobierno.

Los casos más relevantes resueltos en Alemania (1975 y 1993), España (1985), Colombia (2006) y Portugal (2010) en que se ha admitido el aborto bajo el argumento principal de afirmar la inexigibilidad de la mujer para llevar a buen término su embarazo ${ }^{51}$, ha sido sostenido y complementado progresivamente bajo el test de proporcionalidad. Ilustrativo de esta tendencia es la sentencia en que la Corte Constitucional colombiana despenalizó parcialmente el aborto provocado por estimar que obligar a la mujer a finalizar su embarazo suponía para ella una "carga desproporcionada" en relación a sus -así llamadosderechos reproductivos.

La norma legal respecto de la que se solicitaba un pronunciamiento de inconstitucionalidad (algunos artículos del Código Penal) sancionaba el aborto en toda circunstancia, y la Corte legitimó, por vía interpretativa, tres casos en que se justificaba la muerte del embrión. Afirmó que el fin de la interpretación del tribunal era constitucionalmente legítimo al buscar dar protección a los derechos - reproductivos- de la mujer embarazada. También lo estimó idónea porque la afectación del embrión era un medio adecuado para la obtención del fin lícito invocado. Luego, sostuvo que la regulación prevista era necesaria, esto es, la menos lesiva de entre las alternativas disponibles ya que permitía satisfacer los derechos de la mujer contemplando la sanción del aborto para otros casos.

\footnotetext{
48 Günther vON BeRg (1765-1843) expresó que "el poder de policía no puede ir más allá que lo que sus propios fines exige. El poder de policía puede restringir la libertad natural del individuo, pero solo tan lejos como la finalidad legitima lo requiera”, en WürTENBERGER (1999) p. 63.

${ }^{49}$ Krauss (1955) p. 25: "Es, por tanto, inconcebible con el sistema de la Ley Fundamental que al Ejecutivo le estuviera permitido efectuar intervenciones en la esfera privada de los individuos que fueran más lejos de aquello que resulta absolutamente necesario para alcanzar la finalidad legítima”.

${ }^{50} \mathrm{Si}$ pensáramos que las pretensiones reproductivas de la mujer corresponden a derechos fundamentales, tendríamos que admitir que aquellos han sido sacrificados del todo y, por tanto, desconocidos de modo desproporcionado.

${ }^{51}$ Este argumento podría sintetizarse señalando que hay situaciones en que no es posible obligar a una mujer, mediante la amenaza de una sanción penal, a mantener hasta el final un embarazo.
} 
Cumplidas los tres primeras exigencias del test, el camino se encontraba pavimentado para que con ocasión de la proporcionalidad en sentido estricto, el balanceo consecuencialista se inclinara irremediablemente en favor de los derechos reproductivos de la mujer. Esto no solo porque la Corte entendió que el nasciturus no era titular del derecho a la vida (la vida del embrión correspondería más bien a un valor o bien constitucionalmente protegible) con lo cual no habría dudas en preferir un derecho (el de la mujer) que un valor o bien (el embrión). Además, el resultado desproporcionado se producía por el "sacrificio absoluto" que para los derechos reproductivos de la mujer embarazada habría significado la "penalización del aborto en todas las circunstancias" 52 . Paradójicamente, una especie de afán de velar por el resguardo del contenido esencial del derecho de la mujer para abortar; no del embrión que se encuentra en su vientre, cuya vida es, como un todo, un núcleo irreductible a cualquier consideración optimizadora de los bienes básicos de la persona.

Otro ejemplo en que la proporcionalidad contribuye a liquidar el contenido esencial del derecho de reunión so pretexto de preservar el orden público es conocido como el caso de Concentración de Trabajadores de la banca ${ }^{53}$ (1995) resuelta por el Tribunal Constitucional Español (en adelante "TCE”). Los aludidos avisan a la autoridad de la realización de una manifestación pública y la autoridad deniega la posibilidad de llevarla a cabo en el lugar solicitado sin brindar alternativas "relativas al lugar, a la hora o al modo de realización”, que es uno de los puntos objetados por los recurrentes, según lo previsto por la LOC 9/1983, que regula el ejercicio del derecho de reunión. Siguiendo todos los pasos del test en cuestión, la sentencia sostiene que para "preservar el orden público" (fin constitucionalmente lícito) resultaba imprescindible la "prohibición total" del derecho en cuestión, fundado en que las "medidas alternativas hubieran resultado infructuosas" (necesariedad), pues "toda propuesta de modificación del lugar o la hora hubiera desvirtuado el objetivo perseguido" 54 por lo promotores de la reunión.

De más está decir que -sin el referido test de por medio- incluso admitiendo que era necesario prohibir la manifestación del modo señalado, el TCE no justificó la omisión del deber gubernamental de brindar una alternativa de lugar, hora y modo de realización, toda vez que este aspecto constituye, al igual que el derecho a una reunión sin peligro para personas y bienes, una garantía que forma parte del ejercicio regular del derecho de reunión. Dicha garantía es lo que asegura que el aviso a la autoridad para que autorice la manifestación según lo solicitado (o en caso contrario, entregue alternativas para su realización en

\footnotetext{
52 Inconstitucionalidad normas de aborto Código Penal de Colombia (2006): Corte Constitucional de Colombia, 10 de mayo del 2006 (acción de inconstitucionalidad), expresa: "La perspectiva desde la cual se aborda el asunto es otra: dada la relevancia de los derechos, principios y valores constitucionales en juego no es desproporcionado que el legislador opte por proteger la vida en gestación por medio de disposiciones penales. Empero, si bien no resulta desproporcionada la protección del nasciturus mediante medidas de carácter penal y en consecuencia la sanción del aborto resulta ajustada a la Constitución Politica, la penalización del aborto en todas las circunstancias implica la completa preeminencia de uno de los bienes juridicos en juego, la vida del nasciturus, y el consiguiente sacrificio absoluto de todos los derechos fundamentales de la mujer embarazada, lo que sin duda resulta a todas luces inconstitucional".

${ }^{53}$ Begoña Sánchez Espinosa v. Dirección General de Seguridad Ciudadana de Barcelona (2009): Tribunal Constitucional de España.

${ }^{54}$ Begoña Sánchez Espinosa v. Dirección General de Seguridad Ciudadana de Barcelona (2009) F. J. $5^{\circ}$.
} 
lugar y hora distintos) no se traduzca en un permiso para desplegar el aludido derecho fundamental.

En el caso Playas II (2008) $)^{55}$, el Tribunal Constitucional chileno estimó que la aplicación de una disposición legal ${ }^{56}$ que exige a los propietarios de terrenos colindantes con playas de mar, ríos o lagos, facilitar las vías de acceso al público que la autoridad administrativa precise (Intendentes Regionales) si bien afecta el derecho de propiedad de los aludidos titulares, en definitiva, no lo vulneraba por aplicación del test de proporcionalidad. El sentenciador justifica el sacrificio de una de las facultades esenciales del dominio de los propietarios afectados -el uso y goce de la porción de terreno sujeta a servidumbre gratuita- por contemplar la aludida norma legal "un medio necesario, o al menos adecuado, para alcanzar un propósito constitucionalmente legitimo, como es el efectivo disfrute público de bienes que pertenecen a la nación toda" 57.

Aparte de estimar cumplida la idoneidad, añade que el medio previsto "es proporcionado, pues no impone a este [el propietario] sino la obligación de permitir el acceso, indispensable -como ya se vio-para el goce público del respectivo bien nacional. La proporcionalidad del medio empleado aparece de manifiesto en cuanto la disposición establece la obligación en el solo caso de que no existan otras vías públicas de acceso, para los solos fines turísticos y de pesca, y por cuanto el inciso segundo exige al Intendente Regional fijar con prudencia las correspondientes vías de acceso, con audiencia del propietario, arrendatarios o tenedores respectivos y evitando causar daños innecesarios a los afectados" 58 . Asimismo, la sentencia parece destinada a subrayar antes que la licitud del objeto de interés público pretendido por la ley -fines turísticos y de pesca- la inexorabilidad de su satisfacción. Así lo dice el TC: "para que 'la Nación toda' pueda efectivamente usar de los bienes nacionales de uso público, resulta indispensable que pueda acceder a ellos" 59 .

Se advierte que dos de las facultades esenciales del dominio de los propietarios de los terrenos sometidos a servidumbre quedan sacrificados, aunque sea parcialmente, en pos de un objetivo estimado por el Tribunal como de interés público - "que la Nación toda pueda (...) acceder a ellos"- el cual excede con mucho aquellas finalidades legítimas efectivamente previstas por la ley en cuestión - “fines turísticos y de pesca”-. De este modo, la ley que reducía expresamente el acceso público para los fines indicados termina autorizando para todos los habitantes de la nación dicho acceso, abriendo un forado permanente en el derecho de propiedad de los afectados ${ }^{60}$.

Se hace patente en este caso lo ya observado acerca del test en cuestión, al menos desde la perspectiva estructural: el cumplimiento de la idoneidad de la medida gubernamental torna implícita la satisfacción de la legitimidad constitucional de los fines contem-

\footnotetext{
55 Solve et repete IV (2008): Tribunal Constitucional de Chile.

${ }^{56}$ El fallo citado rechaza un requerimiento de inaplicabilidad en contra del artículo 13 del D.L. N $1.939 / 1977$ que impone dichas obligaciones a los referidos propietarios, debiendo el Intendente Regional determinar las servidumbres de paso para facilitar el acceso del público para fines turísticos y de pesca.

57 Solve et repete IV (2008) c. $26^{\circ}$.

58 Solve et repete IV (2008) c. $27^{\circ}$.

59 Solve et repete IV (2008) c. $16^{\circ}$.

${ }^{60}$ Soto Kloss (2010) p. 33.
} 
plados en la ley, con lo cual se omiten en verdad dos de los cuatro requisitos de la proporcionalidad. En la necesidad se es coherente con el test, como quiera que la intervención en el derecho es justificado en el entendido que no hay otro medio menos lesivo (vías públicas de acceso alternativas). No importó sin embargo cuán lesiva hubiese sido la privación parcial de dos aspectos del derecho con tal que dicha injerencia haya sido la mínima para la prosecución de un objetivo público cuya legitimidad constitucional no fue objeto de examen alguno.

Si había alguna esperanza que bajo en análisis del último subprincipio se hubiese estimado que los fines invocados por la ley (turísticos y de pesca) no fuesen lo suficientemente relevantes como para compensar el costo padecido por los titulares del derecho de propiedad, ello se esfuma desde el momento en que al no existir un examen efectivo de la primera exigencia -legitimidad constitucional del objetivo diseñado por el legislador y/o aplicado por el administrador- difícilmente será posible ponderar si el beneficio representado por la envergadura de dichos fines ameritaba incurrir en el costo soportado por los afectados en sus derechos (asumiendo que debe aplicarse una versión optimizadora de la proporcionalidad en estricto sentido).

En los otros aspectos críticos del test -el instrumental y finalista- el afán por privilegiar la satisfacción de la medida estatal por sobre el respeto al derecho comprometido se advierten por añadidura, por lo que no nos referiremos a ellos por ahora.

Como se ha podido observar en los casos expuestos, el empleo del aludido estándar, unido al conjunto de factores expuestos, ha contribuido a dejar mancillados algunos derechos que de otro modo no habrían podido ser vulnerados por la barrera referida a la prohibición de afectar el contenido esencial de los derechos o de impedir su ejercicio so pretexto de intervención regulatoria. En fin, bajo la indicada noción del test, parece claro que lo primordial es que el lícito objetivo de política pública se lleve a cabo en la medida que no sea posible una medida menos gravosa de los derechos involucrados, aunque estos finalmente sucumban ante aquella medida gubernamental ${ }^{61}$.

\section{LA DESPROPORCIÓN DEL TEST: UNA MEDIDA PROPORCIONADA PUEDE HACER SUCUMBIR LOS DERECHOS FUNDAMENTALES}

Hemos visto que una formulación habitualmente indisputada de la proporcionalidad exige que la intervención sufrida por el derecho sea la mínima en consideración al fin lícito pretendido por el Gobierno. Ello, sin embargo, no impide de suyo que dicha medida termine por imponerse absolutamente sobre el derecho sujeto a regulación, infringiendo de este modo la barrera de contención que prohíbe afectar los derechos en su esencia o imponer condiciones que impidan su libre ejercicio.

Lo afirmado puede suceder -como ha ocurrido según vimos- siempre que se estime (a) que no exista interferencia menos lesiva que aquella que sea equivalente a imposibilitar el

\footnotetext{
${ }^{61}$ Como dice, a modo ilustrativo, Martínez López (1985) p. 408: "El contenido de los derechos y libertades fundamentales y en concreto su núcleo esencial puede ser vulnerado por la acción de los Poderes Públicos, no solo cuando proceden a su regulación o a su intervención sobre ellos con sentido restrictivo o constrictivo, sino también cuando dirigen su acción a favorecen su más pleno y efectivo ejercicio" (lo subrayado es nuestro).
} 
ejercicio de la libertad o liquidar parte de su contenido esencial ${ }^{62}$, a condición (b) que el beneficio pretendido por la medida restrictiva sobrepase el costo padecido por el derecho fundamental. Concurriendo copulativamente ambos supuestos, además de los otros habitualmente menos exigentes del test, el camino se encuentra despejado para que el fin considerado lícito se imponga sin más contrapeso al derecho comprometido, al punto de desconocerse con ello el núcleo esencial del mismo y/o la prohibición de afectar su legítimo ejercicio.

Este resultado es por lo demás plenamente coherente con una de las versiones más difundidas del test -la noción de optimización- en cuya virtud la proporcionalidad es aplicada bajo la lógica de un procedimiento de optimización racional del bien común -en lenguaje de Alexy ${ }^{63}$ - en que los derechos fundamentales son observados como un aspecto disponible del interés público, dentro de un balanceo de intereses contrapuestos, de peso equivalente, sometidos a un análisis de costo-beneficio, propio de la proporcionalidad en sentido estricto. De este modo, en una mecánica en que el eventual resguardo del derecho afectado queda reservado para el último paso del test, bajo un criterio utilitarista, los derechos llevan todas las de perder.

$\mathrm{Si}$, en definitiva, la medida de lo proporcionado (lo justo) se encuentra determinada por un resultado en el que los beneficios buscados por la medida de intervención del derecho fundamental compensen los costos padecidos por este, a mayores beneficios observados tanto mayor será el grado de intensidad en la restrictividad del derecho afectado ${ }^{64}$. Esto -dice Cianciardo- "no impide siempre y en todos los casos que el legislador o el administrador violen los derechos fundamentales"65. Así, la paradoja de este test está a la vista: es perfectamente posible que un acto que ha superado todas las exigencias del test, esto es, que una medida formalmente proporcionada termine materialmente sobrepasando el contenido esencial del derecho afectado y sea, por tanto, inconstitucional.

El fenómeno denunciado no obsta a que en varias ocasiones los tribunales hayan resuelto lo contrario, respetando la garantía del contenido irreductible del derecho involucrado o bien, como en el caso chileno, el Tribunal Constitucional haya hecho operativa dicha garantía al aplicar (aunque sea parcialmente) el referido test ${ }^{66}$. Pero esto no se ha logrado

${ }^{62}$ Llama la atención que ZúNigA (2010) pp. 249-272 y DíAZ (2011) pp. 167-206, hayan efectuado una escasa (en el primer caso) o nula (en el segundo) referencia a los previsibles efectos nocivos que la proporcionalidad de cuño optimizador, a la que entusiastamente adhieren, puede traer consigo para la vigencia del contenido esencial de los derechos, garantía expresa de la Carta Fundamental.

${ }^{63}$ La posición de Alexy de no cuestionar (ni tampoco favorecer) la relevancia pública o constitucional del acto restrictivo de derechos es coherente con su idea de que al ser, los derechos y bienes colectivos, caras de una misma moneda (principios) su prevalencia debe resolverse bajo un ejercicio de optimización. Al quedar sujetos a dicho balanceo, el autor cambia la naturaleza de los derechos para hacer posible -proporcionalidad de por medio- su sacrificio ante el interés público. De ahí la consideración de dichos principios como pretensiones, esto es, como intereses prima facie.

${ }^{64}$ BIDART (1984) p. 107.

65 Cianciardo (2007) pp. 285-286. y Prieto Sanchís (1990) pp. 147-148, quien ya había adelantado que "aun cuando la disposición limitadora cuenta a su favor con buenas razones, resultará ilegitima si llega a dañar el contenido esencial o minimo de un derecho".

${ }^{66}$ Covarrubias (2011) p. 425, ilustra dos casos, el Turno gratuito (2007): Tribunal Constitucional de Chile, como Solve et repete IV (2008): Tribunal Constitucional de Chile, en el que dos indiscutidos y altisonantes fines de interés público -la "eficacia y seguridad" de las sanciones administrativas, adoptadas "en defensa de la vida y de 
gracias a la proporcionalidad sino que a pesar de ella o bien conforme anociones no utilitaristas del aludido test. Los otros casos en que se ha respetado aquella reserva de justicia y seguridad manifestada en el núcleo de todo derecho fundamental lo ha sido por consideraciones indisponibles de dignidad humana, aunque sobre este punto no nos pronunciaremos por ahora ${ }^{67}$.

Ya hemos expuesto -en el acápite precedente- un par de casos en que la supuesta primacía del interés público en un análisis de optimización se impone incondicionadamente sobre el derecho intervenido al punto de hacerlo sucumbir del todo, por lo que no volveremos sobre los ejemplos ya señalados. Nos centraremos, en un afán propositivo, en subrayar que conforme a una perspectiva menos utilitarista del test hay casos en que es posible aplicar la proporcionalidad respetando el contenido esencial de los derechos fundamentales sujetos a regulación.

\subsection{Cuando la proporcionalidad contribuye a proteger el Contenido} ESENCIAL: LA NOCIÓN NO CONSECUENCIALISTA DEL TEST

Vimos que la noción utilitarista de la proporcionalidad, la denominada "optimising conception", tiene una variante -en el derecho inglés y comunitario europeo- que contiene elementos que se avienen más con una idea que permite conciliar el empleo del test con resultados que no sean desproporcionados o injustos en términos del aseguramiento de un núcleo irreductible en el ejercicio de los derechos fundamentales. ¿Es posible salvar del utilitarismo un estándar que, hemos dicho, produce efectos consecuencialistas? Estimamos que la respuesta es afirmativa habida consideración de las siguientes razones y no obstante algunas reservas que efectuaremos al respecto.

Como lo señaláramos precedentemente, si el estándar judicial inglés, en De Freitas $(1999)^{68}$ excluyó expresamente del test en cuestión el subprincipio de proporcionalidad en sentido estricto, sustituyéndola por una noción más afín a la primitiva prohibición por exceso, el terreno se encontraba fértil para ser abonado por algunas propuestas doctrinarias que terminaran por desplazar, aunque sea en el ámbito conceptual, aquella exigencia estrictamente utilitarista de la proporcionalidad.

En efecto, cuando Clayton y Tomlinson se refieren al último requisito del test como una exigencia que tiene por objeto impedir "cargas o daños excesivos" 69 en perjuicio de los administrados; Wade y Forsyth estiman que el referido estándar "ordena que las medidas administrativas no sean más drásticas que lo estrictamente necesario para obtener el resultado

la salud" y "la asistencia jurídica gratuita" - no lograron imponerse sobre el contenido esencial del derecho de acceso a la justicia y de la libertad de trabajo, respectivamente.

${ }^{67}$ Hartwig, Matthias (2010): "La 'Proporcionalidad' en la Jurisprudencia del Tribunal Constitucional Federal de Alemania”, en Eduardo Ferrer Mac-Gregor y otros (Coord) La justicia constitucional y su internacionalización ¿Hacia un ius constitucionale commune en América Latina?, Tomo I, México, p. 790. El autor señala que el TC Alemán "establece límites absolutos para la ponderación cuando la intervención sobrepasa una cierta intensidad y viola el núcleo del derecho fundamental (...). Otro límite fijo es el artículo $1^{\circ}$., que protege la dignidad humana (...). Hasta ahora la mayoría en la doctrina y el Tribunal Constitucional declaran la dignidad no sometida a una ponderación".

${ }^{68}$ De Freitas v. Permanent Secretary of Ministry of Agriculture, Fisheries, Land and Housing (1991).

${ }^{69}$ Clayton y Tomlinson (2000) p. 298. 
querido"70 y, Lester y Pannick lo asumen como una condición de "justo equilibrio" (fair balance $)^{71}$, no es descabellado pensar que constituirá una labor más dificultosa conducir el referido estándar a un irremediable balanceo de intereses, presidido por un predominante criterio de mensurabilidad en que el interés público termine por sacrificar los derechos intervenidos. Mantenemos esta afirmación en el plano estrictamente conceptual toda vez que desconocemos si actualmente las cortes del Reino Unido han hecho suyo la aplicación del referido test en un sentido distinto al señalado.

Con todo, en la línea indicada, algunos autores han reconocido que -en el ámbito regulatorio económico- es posible admitir casos excepcionales en que un insuperable interés público ("overriding public interest") puede llegar a justificar una afectación seria de los derechos del regulado ${ }^{72}$, generalmente la libertad de emprender actividades económicas y el derecho de propiedad. En cambio, encontrándose involucrados otros derechos fundamentales de naturaleza inconmensurable -y que Elliott denomina absolutos- el autor sugiere que ningún proceso de balanceo resulta apropiado en tales $\operatorname{casos}^{73}$.

Paralelamente, en el ámbito de la justicia continental europea, la Corte Europea de Derechos Humanos (Tribunal de Estrasburgo) como la Corte Europea de Justicia (Tribunal de Luxemburgo) exhibe algunos casos en que no obstante aplicarse el balanceo vía test de proporcionalidad, el resultado del método halla su contención en el respeto al contenido esencial de los derechos reconocidos por la Convención Europea, sujetos a restricción estatal. Así lo ha entendido en ocasiones el Tribunal Europeo de Derechos Humanos (en adelante, "TEDH" o "Tribunal de Estrasburgo"), especialmente en casos en que se ha invocado el derecho al matrimonio y a fundar una familia ${ }^{74}$ (art. 12 de la Convención Europea), el derecho a gozar de elecciones libres $^{75}$ (art. 3) y el derecho a un juicio justo ${ }^{76}$ (art. 6 párr. 1), entre otros ejemplos.

$\mathrm{El}$ argumento subyacente en los casos señalados ha sido que las regulaciones previstas por la autoridad restringían los derechos involucrados hasta el punto de lesionar su contenido irreductible. Pero lo más interesante es que en algunos de ellos, el Tribunal de Estrasburgo concluyó que existía una vulneración al contenido esencial del derecho a sufragio atendido que las medidas adoptadas eran desproporcionadas ${ }^{77}$ o derechamente afectaban el núcleo esencial de este derecho, sin siquiera haber acudido a la consideración del propósito legítimo de la restricción ${ }^{78}$. En otros casos, la referida instancia jurisdiccional ha estimado

\footnotetext{
70 WADE y FORYSTH (2004) p. 366.

${ }^{71}$ Lester y PANick (2004) p. 89.

72 Varios autores Arancibia (2011) pp. 134-165; Elliott (2006) p. 318).

73 Elliott (2001) p. 173.

${ }^{74}$ Rees $v$. United Kindgom (1987), en que se sostuvo que quedaba entregado al margen de apreciación de cada estado, pero que en caso alguno la ley podía lesionar el núcleo esencial ("the very essence") de este derecho. Aunque en Godwin v. UK (2002), el Tribunal de Estrasburgo cambiaría de criterio.

75 Matthieu-Mohin v. Belgium (1988) en que se sostuvo que las condiciones impuestas por el Estado no podían “perjudicar los derechos en cuestión al punto que lesione su contenido esencial y los prive de efectividad". En sentido análogo: Zdanoka v. Latvia (2000) y Selim Sadak v. Turkey (2003).

${ }^{76}$ Ashingdame v. United Kingdom (35373/1971).

77 Selim Sadak v. Turkey (2003) y Zdanoka v. Latvia (2000).

${ }^{78}$ Matthews v. United Kingdom (1999) y Aziz v. Cyprus (2001).
} 
que no hay razón alguna para legitimar determinadas restricciones al derecho a un juicio justo sin referirse al principio de proporcionalidad ni tampoco al contenido esencial de los derechos ${ }^{79}$.

De modo análogo se ha fallado también por el Tribunal de Luxemburgo en materia regulatoria económica en que se ha estimado que el derecho del reclamante "es seriamente afectado, o la medida es exigida mediante una penalidad severa o a través de un medio excepcionalmente duro" 80 .

Ello ha ocurrido en casos como Hauer v. Land Rheinland-Pfalz (1979), un caso ilustrativo en que si bien se estimó que las medidas restrictivas eran consistentes con los objetivos perseguidos por la comunidad europea, aquellas no podían perjudicar la esencia del derecho: "Debe reconocerse por tanto que la restricción impuesta al ejercicio del derecho de propiedad mediante la prohibición de nuevas plantaciones de vides, establecida para un período limitado por el Reglamento $n^{\circ} 1162 / 76$, está justificada por los objetivos de interés general perseguidos por la Comunidad y no vulnera la substancia del derecho de propiedad tal como lo reconoce y garantiza el ordenamiento jurídico comunitario" 81 .

En la misma línea, Germany v. Council (1994) estimó que la satisfacción de uno de los fines de la Comunidad Europea -la organización ordenada del Mercado- justificaba la regulación tarifaria, afectando el ejercicio del derecho de propiedad y la libertad de comercio, en el entendido que tales restricciones "no constituyan (...) una intervención desmesurada e intolerable que afecte a la propia esencia de los derechos asi garantizados" 82 , resolviendo que tal grado de interferencia no se había producido en este caso.

Lo precedentemente expuesto evidencia, no sin algunas reservas, que hay elementos teóricos y prácticos que contribuyen a una formulación del test -particularmente de la proporcionalidad en sentido estricto- que admitiendo legítimas restricciones a los derechos por motivos de bien común garantice que dichas injerencias dejen a salvo el contenido mínimo del derecho, evitando que en nombre de un supuesto interés público termine llevándose al despeñadero a los derechos fundamentales intervenidos por la regulación estatal.

No es muy trabajoso comprender que si una proposición del test de proporcionalidad prohíbe que la intervención de la autoridad sea excesivamente gravosa o dañina, ello supone exigir que el diseño y aplicación regulatorios que limiten los derechos fundamen-

\footnotetext{
${ }^{79}$ Geouffre de la Pradelle v. France (1987) y Philis v. Greece (1998).

${ }^{80}$ De BúrCa (1993) p. 146.

${ }^{81}$ Hauer v. Land Rheinland-Pfalz (1979) párr. 30; Arancibia (2011), al analizar estos y otros casos similares, p. 145, concuerda en que la Corte Europea de Justicia exhibe una línea en que las limitaciones a la actividad comercial no pueden vulnerar la esencia de los derechos de propiedad y, en caso alguno, pueden imponer restricciones equivalentes a prohibir una industria lícita o a privar del derecho a ejercer una determinada actividad económica.

${ }^{82}$ Germany v. Council (1994) párr. 78. Dice que tales derechos "no constituyen prerrogativas absolutas, sino que deben tomarse en consideración con su función en la sociedad. Por consiguiente, pueden imponerse restricciones al derecho de propiedad y al libre ejercicio de una actividad profesional en especial, en el marco de una organización común de mercados, siempre y cuando estas restricciones respondan efectivamente a objetivos de interés general perseguidos por la Comunidad y no constituyan, habida cuenta del objetivo perseguido, una intervención desmesurada e intolerable que afecte a la propia esencia de los derechos asi garantizados (sentencias de 11 de julio de 1989, Schräder, 265/87, Rec. p. 2237, apartado 15; de 13 de julio de 1989, Wachauf, 5/88, Rec. p. 2609, apartado 18, y sentencia Kühn, antes citada, apartado 16)".
} 
tales en pos del interés público no acaben soslayando el contenido esencial de los derechos afectados o impidan su libre ejercicio ${ }^{83}$. Puesto al revés: ¿Qué “fair balance” puede existir si la revisión judicial inclina la balanza en desmedro absoluto de una medida gubernamental que es indispensable para el bien común por estimar que los derechos fundamentales invocados ni siquiera pueden ser "salpicados" por tal acto?

En efecto, si la proporcionalidad es una exigencia de justicia, proporción y equilibrio, no es admisible que en nombre del bien común se prive a las personas de sus derechos fundamentales así como tampoco es justificable perjudicar la satisfacción del interés público bajo el pretexto de dejar a aquellos derechos intocados ${ }^{84}$. En el derecho chileno, Nogueira $^{85}$, Bertelsen ${ }^{86}$, Martínez Estay ${ }^{87}$, entre otros, comparten que la labor balanceadora entre los derechos fundamentales o entre estos y los fines legítimos de políticas públicas no pueden mancillar el contenido irreductible o esencial de los derechos sujetos a regulación, en virtud del artículo $19 \mathrm{~N}^{\circ} 26$ de la Carta Fundamental.

La formulación expuesta contribuye a que -en el estricto ámbito de regulación de derechos de contenido patrimonial y/o económico- la proporcionalidad pueda brindar aquella necesaria combinación de ductilidad, oportunidad y flexibilidad que se requiere en este ámbito con la indispensable seguridad y previsibilidad jurídicas brindada por las Cortes. De este modo, al exigirse que el acto de restricción estatal no vaya más allá de lo estrictamente necesario para satisfacer el fin público, ha de entenderse que la medida de injerencia regulatoria en el derecho fundamental se encuentra sujeta al respeto al contenido mínimo de aquel y no a la prevalencia incondicionada del interés público ${ }^{88}$.

Lo anterior enfrenta, al menos, dos serios escollos para su efectiva aplicación. Primero, un contexto en que la proporcionalidad no es considerada como uno de los tantos métodos a acudir sino como una vía que aparece como insuperable e ubicua ${ }^{89}$ a utilizar en un orden constitucional articulado por disposiciones de derecho fundamental (principios, en clave Alexiana) que no establecen un grado o medida exacta de satisfacción y que se

\footnotetext{
${ }^{83}$ Nogueira (2010) p. 359, afirma que en la proporcionalidad se examina si la regulación restrictiva "constituye una medida equilibrada y justa entre el beneficio para el bien común que se obtiene de la limitación y el perjuicio que sufre el derecho afectado". En similar sentido, Arancibia Mattar (2011) p. 202, al sugerir que "el impetu que subyace al test en su totalidad es fundamentalmente el propósito de impedir el logro del fin legitimo por medios que resulten excesivos a los derechos de una persona".

${ }^{84}$ Las bases de una propuesta fundada en el anclaje constitucional chileno que permite conciliar las exigencias que impone el bien común con el respeto el contenido esencial de los derechos de las personas, en CovarRUBIAS (2011) pp. 398-405.

85 Nogueira (2010) p. 397. Recientemente, en Nogueira (2011), el autor ilustra la relación entre proporcionalidad y contenido esencial en la jurisprudencia de la Corte Interamericana de DDHH en materia de libre expresión.

${ }^{86}$ BeRTELSEN (2009) pp. $72-77$ y p. 101.

${ }^{87}$ Martínez Estay (2011) pp. 205-209.

88 Por el contrario, en caso de adoptarse la versión consecuencialista de la proporcionalidad en estricto sentido, lo coherente con nuestro planteamiento sería comprender que la labor balanceadora del test permite indagar si la limitación a un derecho o bien es o no justificada, pero que dicha medida de injerencia solo será constitucional si no pasa a llevar el mínimo protegido por el contenido del derecho comprometido.

${ }^{89}$ Alexy (2003) p. 436.
} 
muestran prima facie como contradictorios, por lo que conflictuadas entre sí, el balanceo optimizador resulta un imperativo difícil de soslayar ${ }^{90}$.

El segundo escollo -del que no es posible hacerse cargo aquí- está representado por aquella errónea visión que plantea a lo colectivo y social (interés público) en términos opuestos e irreconciliables con un legítimo interés individual (derechos), de modo que una vez enfrentados no cabe sino hacer prevalecer sin contrapeso a lo primero ${ }^{91}$. Es indudable que el interés general prevalece sobre el interés particular, pero de ello no se sigue necesariamente que todo derecho fundamental sea ni represente únicamente una pretensión individual. Tampoco que el bien público haya de imponerse de manera incontrarrestable en contra del bien privado.

\section{LA AMENAZA DE LA PROPORCIONALIDAD: SU ENTRAMADO CONSECUENCIALISTA DESCONOCE LA EXISTENCIA DE DERECHOS FUNDAMENTALES INVIOLABLES}

Ya se ha adelantado que en el núcleo del test -la proporcionalidad en sentido estricto- subyace la noción de que la licitud o ilicitud constitucional de una medida gubernamental que restrinja derechos fundamentales suele determinarse según algún modo de cálculo o ponderación entre los derechos fundamentales y los denominados bienes o fines de relevancia constitucional, hasta el punto de admitirse el sacrificio de los primeros (derechos) a manos de los segundos (interés público) o de derechos que puedan identificarse con este.

Esta lógica se advierte, como hemos visto, no solo en el entramado estructural del test sino también en el vocabulario empleado por aquellos que lo aplican o promueven su aplicación, quienes prefieren utilizar expresiones como "interés", "valor", "costo", "beneficio", "peso", entre otras tales como "suficiente" y "adecuado" 92 . Ello en vez de emplear un lenguaje acerca de lo "justo”, “jurídico” o "antijurídico” donde prima la consideración de lo cualitativo por sobre un análisis de tipo cuantitativo respecto de los derechos. Un léxico de tipo mensurable acerca de los derechos fundamentales ciertamente dificulta la labor de determinar el contenido indisponible de los mismos para efectos de brindar su protección.

Aparte de las objeciones ya desarrolladas en el plano analítico acerca del test en cuestión, cabe añadir la siguiente de índole jurídico-moral: el subprincipio de proporcionalidad en sentido estricto (la versión optimizadora) es consecuencialista en cuanto supone de suyo la negación de la existencia de derechos inviolables. Así lo reconoce Alexy al observar los derechos fundamentales como "principios" consistentes en "exigencias de optimización" que

\footnotetext{
${ }^{90}$ Martínez Alarcón (2008) p 11.

${ }^{91}$ Prado (2007) p. 84 y Covarrubias (2011) pp. 420-425, quien afirma en clave constitucional el erróneo supuesto de existir una contraposición entre la satisfacción del bien común y el respeto a los derechos fundamentales.

92 Webber (2010) p. 180, quien critica este léxico en la interpretación de derechos fundamentales. En Chile, por el contrario, García (2011) p. 116, estima adecuado el test "a la hora de ponderar los costos y beneficios de una regulación que afecta derechos y libertades de naturaleza económica; y (...) por el desarrollo que tiene y puede tener en sede de inaplicabilidad, del análisis de los elementos factuales presentes en un determinado caso, pueden surgir, de manera obvia el juego de costos y beneficios, privados y sociales, que están en juego".
} 
deben ser cumplidos en la medida de lo "legal y factualmente posible" 93 , por lo que difícilmente este planteamiento admite la posibilidad de concebir derechos inviolables a todo evento. Entendemos por estos a aquellos derechos absolutos que no admiten excepción ${ }^{94}$ o que admitiéndolas (por lo que no son absolutos) puede estimarse que son igualmente inviolables en un aspecto nuclear o sensible del mismo ${ }^{95}$.

En efecto, si este estándar asume su inevitabilidad en el campo de los derechos -ya sea por considerar que estos son "mandatos de optimización sujetos a balanceo", ya sea por estimar que en el referido ejercicio se ha de observar cómo "el costo padecido por el derecho se ve compensado por el beneficio equivalente a la satisfacción del interés público"- deviene entonces como corolario ineludible que los derechos sometidos a este cálculo ponderativo quedarán con toda probabilidad a expensas del sacrificio en pos de un interés estimado superior.

Así, para la proporcionalidad de cuño optimizador no existen derechos fundamentales inviolables sino solo principios cuya satisfacción ha de cumplirse en la medida de la posible y en diverso grado ${ }^{96}$. Este empeño balanceador -además de eliminar el carácter inalienable de los derechos $-{ }^{97}$ contribuye a que aquellos que son inviolables por constituir manifestaciones de bienes humanos básicos (vida, conciencia, etc.) o que lo son por su naturaleza inconmensurable ${ }^{98}$ con otros derechos o bienes (vida, intimidad, debido proceso, honra, etc.) puedan a la postre ser desconocidos en un caso concreto. A este resultado se llega como consecuencia de una labor que, en palabras de Glendon, equivale a "tratar a los derechos fundamentales como items de un menú del cual uno escoge su favorito, ignorando el resto" 99.

La objeción de fondo, que vivifica la regla paulina de la tradición central del Derecho, la explica Finnis al expresar como exigencia de razonabilidad práctica que "es siempre irrazonable elegir directamente contra cualquier bien básico", deber este que es correlativo a algunos "derechos-exigencias sin excepciones o absolutos"100. La aludida máxima "es la colum-

93 Alexy (2002) pp. 44-61. Así, todos los derechos gozarían de equivalente valor moral. Siguiendo esta línea Grimm (2007) p. 394, confirma la idea de que en Alemania "[e]l Tribunal Constitucional no reconoce una jerarquía entre los diversos derechos fundamentales.

${ }^{94}$ A modo ilustrativo, la Convención Europea de Derechos Humanos establece 4 derechos absolutamente reconocidos: Nadie podrá ser sometido a tortura o a un trato o castigo inhumano o degradante (art 3); Nadie podrá ser sometido a esclavitud o servidumbre (Art 4 (1)); Nadie podrá ser condenado por una acción o una omisión que, en el momento en que haya sido cometida, no constituya una infracción según el derecho nacional o internacional (Art 7(1)); Igualmente no podrá ser impuesta una pena más grave que la aplicable en el momento en que la infracción haya sido cometida (Art 7(1)). La prohibición de "ser privado de su vida intencionadamente" solo tiene como excepción, en dicho texto, "la pena capital dictada por un Tribunal al reo de un delito para el que la ley establece esa pena” (Art. 2 (1)).

95 Estoy pensando en aspectos sensibilísimos de la intimidad de una persona ordinaria (vida sexual o estado de salud) en los términos formulados por el artículo 2, letra g) de la Ley 19.628 de Protección a la Vida Privada o en los mínimos resguardos para un debido proceso (incluso en caso de guerra).

${ }^{96}$ Alexy (2010) p. 21.

97 Cianciardo (2000) p. 118, acota que "si hay algo que ha caracterizado al discurso de los derechos humanos desde su aparición es, justamente, su resistencia a la postergación”.

98 GEorge (1989) p. 252-253, afirma que la inconmensurabilidad "significa que es imposible decir que un estado de cosas producido mediante la violación de derechos fundamentales es mejor para la sociedad que el estado de cosas que se hubiera obtenido en caso que los derechos hubieran sido respetados".

${ }^{99}$ Glendon (2008) p. 928.

100 Finnis (2000) p. 253 (por ambas citas). Una interesante y reciente crítica al test, formulada a partir de Fin- 
na vertebral de los sistemas jurídicos decentes. Pues un sistema jurídico decente excluye incondicionalmente la occisión o el daño de personas inocentes como medio para cualquier fin, ya sea público o privado"101. En una línea similar se han pronunciado otros autores contemporáneos como George ${ }^{102}$ y Sandel ${ }^{103}$, e incluso liberales perfeccionistas como Raz ${ }^{104}$, entre otros $^{105}$, quienes también han criticado el consecuencialismo ético aplicado a los bienes humanos básicos.

Desde este planteamiento, la proporcionalidad, en su versión optimizadora, se advierte como un método ciertamente inadecuado para la eficaz tutela de derechos fundamentales absolutos. Esta posición se sitúa ciertamente en las antípodas de aquella concepción liberal de corte colectivista-consecuencialista que sostiene que los derechos pueden, en el contexto de la ponderación balanceadora, ser legítimamente eliminados "en aras de bienes colectivo" 106 (Alexy) así como también, a la inversa, de aquella noción individualista bastante difundida y que proclama que "los derechos deberían ser respetados aun cuando su ejercicio le hiciera a la comunidad estar peor"107 (Dworkin), lo que equivale a sostener que las políticas públicas (policies) que persiguen el bien común no podrían siquiera afectar a los derechos fundamentales, debiendo estos permanecer prácticamente intocados.

Equidistante de ambos extremos liberal-colectivista pensamos que aquellos actos de autoridad estatal que persiguen la satisfacción del bien común o de un aspecto de él (salud, orden, seguridad o moralidad públicas) pueden interferir legítimamente en los derechos a condición de que su contenido esencial no sea completamente postergado. Subyace a esta noción una comprensión de los derechos fundamentales como conducta objetivamente debi$d a^{108}$ antes que como pretensión subjetiva desprovista de toda concepción de bien ${ }^{109}$.

Este planteamiento, junto con asegurar el carácter fundamental de los derechos, permite conciliar las indispensables exigencias que el bien común impone con la protección a la intangibilidad de los derechos de la persona, perspectiva esta que, hemos señalado, se encuentra adecuadamente formulada en la Constitución chilena que ve a la cláusula de

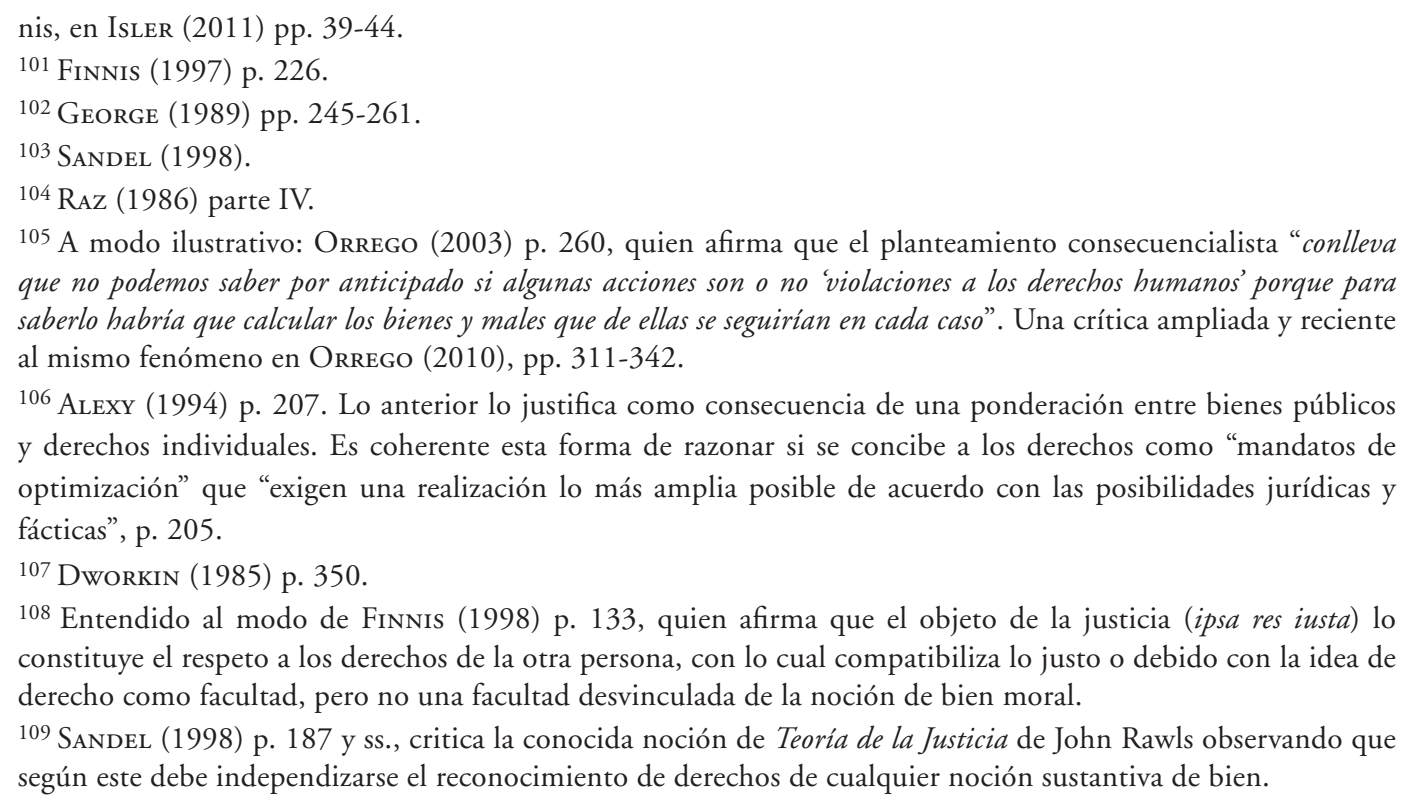


prohibición de afectar el contenido esencial de los derechos fundamentales como punto de encuentro entre el adecuado ejercicio de las políticas públicas y el respeto a aquellos ${ }^{110}$.

A final de cuentas, bajo el predominio del aludido test no habrá respuestas categóricas si están en juego derechos inviolables o aspectos indisponibles o inconmensurables de otros derechos no absolutos. Un ejemplo dramático de lo señalado es el caso Suresh v. Canada (2002) ${ }^{111}$ en que la Corte Suprema canadiense rehúsa afirmar de modo terminante que el derecho a la vida y a la seguridad de la persona -bajo la Carta Canadiense de Derechos y Libertades - impide al Estado extraditar a personas a un país donde podrían ser sometidas a métodos de tortura. De hecho, la Corte admitió "la posibilidad que bajo circunstancias excepcionales" dicho escabroso procedimiento "podría justificarse (...) como consecuencia del proceso de balanceo dispuesto (...) en la Carta"112 de Derechos Canadienses, en las señaladas circunstancias.

Lo grave no estriba tanto en la posibilidad de que otro país termine torturando como consecuencia de un procedimiento de extradición bien afinado, puesto que la responsabilidad recae en el país torturador, no en el país que autoriza el aludido procedimiento. El punto es que la conclusión de poner en entredicho el derecho a no ser torturado se sigue como consecuencia del encadenamiento lógico derivado de la prevalencia de la proporcionalidad, como quiera que la suerte de los derechos quedará siempre condicionada al resultado del aludido balanceo optimizador, entre cuyas posibilidades siempre estará que la tortura deje de ser considerada una prohibición absoluta ${ }^{113}$. Esto se condice, por lo demás, con el planteamiento de Alexy en cuanto a que "la convicción de que debe haber derechos que aún en las más extremas circunstancias no sean sobrepasados (...) no puede ser sostenido en el derecho constitucional"114.

Así, el test de proporcionalidad y su consiguiente utilitarismo de cuño consecuencialista contribuye a debilitar la Seguridad como la Justicia -bienes perennes del Derecho- como quiera que sitúa a los referidos principios en una posición de inestabilidad y de maleabilidad susceptibles de ser tratados como meros instrumentos al servicio de fines ulteriores.

Parece quedar de manifiesto que el test de proporcionalidad no constituye una estándar meramente neutral de argumentación, desprovisto de pretensiones normativas, por lo que su utilización en el marco de los derechos fundamentales exige el empleo de resguardos indispensable para proteger los derechos humanos absolutos o bien aquellos aspectos particularmente sensibles que aquellos derechos que sin ser absolutos gozan igualmente de un contenido mínimo que no puede quedar sujeto a los vaivenes de un balanceo que no comprende la naturaleza muchas veces inconmensurable de los bienes humanos involucrados ${ }^{115}$.

\footnotetext{
${ }^{110}$ Este planteamiento se encuentra formulado aunque preliminarmente en CovarRubias (2011) pp. 398-405.

111 Suresh v. Canada (2002).

112 Suresh v. Canada (2002) párr. 78.

113 BRugger (2000) p. 661 y ss., justifica, conforme al test de proporcionalidad, la tortura aplicada por el Estado en determinadas circunstancias.

114 Alexy (2002) p. 196.

115 En este sentido: Webber (2010), p. 193. La objeción de inconmensurabilidad ha procurado ser respondida por los siguientes partidarios -algunos con reservas- del test: Bernal (2003) pp. 176-182 y Zorrilla (2007) p. 309 y ss., y recientemente por ZuCCA (2011), pp. 21 y ss.
} 
En el contexto señalado, no cabe sino destacar la jurisprudencia que en ocasiones ha sostenido el Tribunal Constitucional Federal alemán en cuanto a establecer límites absolutos para el balanceo, ya sea "cuando la intervención sobrepasa una cierta intensidad y viola el núcleo del derecho fundamental"116 o bien cuando ha "declarado la dignidad no sometida a ponderación"117.

Uno de los casos en que lo señalado ha quedado patente es el de la Ley de Seguridad Aérea (2006) ${ }^{118}$ en que el Tribunal Constitucional alemán resolvió que el Estado no permite amparar, ni siquiera en una situación excepcional como la ocurrida el 11 de septiembre de 2001, el asesinato de pasajeros inocentes de un avión (mal supuestamente menor) con el fin de evitar otras eventuales víctimas de mayor número (un mal supuestamente mayor). Ello, fundado en la violación del artículo 1 (1) de la Ley Fundamental ("La dignidad humana es intangible") al tratar a los pasajeros "como partes del avión que tiene que ser destruido desde el momento en que se ha transformado en un arma" ${ }^{119}$ en vuelo ${ }^{120}$.

Otro relevante caso en que el Tribunal Constitucional alemán estimó que ni siquiera un preponderante interés público era capaz de infringir una esfera tan íntima como aquella que estaba en juego con la modificación del Código Procesal Penal, que autorizaba severas medidas de injerencia en las conversaciones del hogar. Según la sentencia, "[l]a Constitución solo autoriza medida de vigilancia que no violen la dignidad humana (...)"121. Luego añade: "Hay una estrecha conexión entre la inviolabilidad del hogar y la dignidad de hombre, que establece el deber del estado de respetar una esfera puramente personal. Las personas tienen que estar seguras que la confidencialidad para comunicarse es segura en sus espacios privados. En esta esencial esfera intima, cada uno es protegido de modo que, sin excepción alguna, no es permitida la vigilancia acuistica del hogar en esta intima esfera. Ni siquiera intereses públicos predominantes pueden justificar una injerencia sobre esta esfera de la intimidad"I22.

\section{LA ILUSIÓN DE LA PROPORCIONALIDAD: SU PRETENDIDA UNIVERSALIDAD}

En el acápite precedente hemos visto que, salvo excepciones (la dignidad humana o el contenido esencial de los derechos), para el test de proporcionalidad de cuño consecuencialista no hay derechos fundamentales inviolables sino solo principios (cuyo resultado dependerá de la ponderación balanceadora) por lo que asumido un estatuto inamovible para ciertos derechos, el referido estándar se advierte inconducente sin los indispensables resguardos a los que ya nos hemos referido aunque sea tangencialmente. En esta parte,

\footnotetext{
116 Hartwig (2010) p. 790.

117 Bockenforde (2003) pp. 89 y ss., citado por Hartwig (2010) p. 790.

118 Reclamo de constitucionalidad de la Ley antiterrorista alemana (2006).

119 Reclamo de constitucionalidad de la Ley antiterrorista alemana (2006), citado por Lepsius (2006) p. 767.

120 Paradójicamente, la misma sentencia dice que "las leyes pueden vulnerar el derecho a la vida en caso que estén legalmente justificadas bajo el principio de proporcionalidad”. Esto se explica (aunque no se justifica a nuestro juicio) porque para el TC Alemán, la dignidad es absoluta en cambio la vida no lo es.

${ }^{121}$ Reclamo de constitucionalidad de la Ley de escuchas en los hogares (2004) párr. 132.

122 Reclamo de constitucionalidad de la Ley de escuchas en los hogares (2004) párr. 134, citado asimismo por STENDER-Vorwachs (2004) p. 1344.
} 
observaremos si la pretensión de universalidad que el aludido estándar promete resulta aplicable a aquellos derechos fundamentales que no son absolutos, esto es, que admiten ciertos grados de restricción.

La aludida pretensión de universalidad o de inevitabilidad ha sido sostenida, entre otros, por Alexy, quien ha dicho que tratándose de derechos fundamentales, la proporcionalidad es inevitable dado que "no hay otro modo racional en el que la razón para limitar puede ser puesto en relación con un derecho fundamental"123. En otra ocasión ha expresado que el balanceo "es la ubicuidad en el Derecho"124. En una línea similar, Beatty ha dicho que el referido método constituye una parte esencial e inevitable de todo texto constitucional así como un "criterio universal de constitucionalidad"125. Las citadas afirmaciones, reiteramos, no se comprenden sino en el contexto de derechos que son considerados como principios optimizables antes que como reglas (que deben cumplirse sin más).

Varias objeciones podrían extenderse sobre la proclamada inevitabilidad del test, entre ellas, su supuesta neutralidad. Por ahora más bien nos referiremos sobre la idoneidad de balancear -bajo un patrón único de medida- derechos fundamentales y bienes que no son conmensurables entre sí. ¿Cuánta pérdida del derecho a un debido proceso vale la vigencia de la Seguridad Nacional? ${ }^{126}$. La pregunta formulada expresa con claridad uno de los problemas más complejos subyacentes en este método: la posibilidad de comparar derechos, bienes e intereses bajo un parámetro de medición cuantitativo. Si ya es problemático medir bienes inmedibles, el problema se agudiza aún más si dicha labor ponderativa se pretende llevar a cabo bajo un único estándar de medición y lo que se pretende comparar son bienes humanos.

Uno de los precursores contemporáneos del test -Krauss- se sinceraba al señalar que este "consiste en relacionar dos o más cantidades que pueden ser sopesadas con un patrón común, esto es, que son comparables y ajustadas unas a otras de un cierto modo"127. ¿Qué decir sobre otros autores, ya precedentemente citados, que conciben la proporcionalidad en estricto sentido como un ejercicio de ponderación de los beneficios de la medida estatal impuesta versus los costos de haber incurrido en la vulneración de un derecho fundamental para concluir en qué lado se produce el mayor bien?, o bien la otra perspectiva en que debe analizarse en qué medida la pérdida del derecho afectado se ve compensada por el beneficio invocado por la autoridad ${ }^{128}$.

Dicho lo anterior, salta a la vista lo contraproducente que sería analizar, en términos de costo-beneficio, si el indiscutible fin estatal de la prevención de la pornografía infantil justifica escudriñar la intimidad de los cibernautas por la vía de conocer los sitios que visitan en internet. ¿Puede el interés público en proteger la moralidad de los menores de edad

\footnotetext{
${ }^{123}$ Alexy (2002) p. 74.

${ }^{124}$ Alexy (2003) p. 436.

125 BeAtтy (2004) p. 162. En similar sentido, Kumm (2010) p 144, quien señala que a diferencia del método tradicional de adjudicación constitucional (ley, historia fidedigna, jurisprudencia), que hoy juega un modesto rol, "el corazón operativo de la gran mayoría de los casos de derechos humanos o constitucionales es el test de proporcionalidad".

${ }^{126}$ Rivers (2006) p. 190.

127 Krauss (1955) p. 14.

128 Thomas (2000) p. 85
} 
dejar entregada la vida privada a un cálculo de proporcionalidad? ${ }^{129}$. O, más problemático todavía, ¿en qué sentido podría concluirse que el beneficio obtenido por una política pública de salud puede compensar el costo de dejar sin tutela a la criatura que se encuentra en el vientre materno? ${ }^{130}$.

Ilustrativo resulta en este sentido la opinión de dos profesores que al comentar la sentencia píldora del día después (2008) ${ }^{131}$, y fundados en el test de proporcionalidad ${ }^{132}$, critican que el Tribunal Constitucional debió haber ponderado "el costo de una incierta afectación de la vida del embrión versus el costo de una reducción de la eficacia de una politica de prevención del embarazo adolescente o de una intervención estatal para disminuir los efectos negativos del delito de violación" ${ }^{33}$, aunque no explican ni entregan los elementos acerca de cómo dicho trabajoso cálculo habría que llevarse a cabo.

En otro orden de derechos, ¿es conmensurable la libertad de vestir el velo islámico con la pretensión estatal de promover la laicidad? Y para dar algunos ejemplos de derechos que no son absolutos: ¿Qué garantías del debido proceso legal pueden ser omitidas en una situación de convulsión nacional?

La objeción de fondo estriba en que los bienes que muchos derechos fundamentales manifiestan no son susceptibles de someterse a estándares que prestan utilidad en el ámbito técnico-cuantitativo antes que en la esfera del razonamiento de bienes morales ${ }^{134}$. Lo que en estos casos se pretenden "medir" no son intereses ni cantidades sino cualidades morales de bienes humanos relevantes. Por eso es que en este contexto de aspectos inconmensurables del bienestar humano resulta tan contraintuitivo el empleo de un método que, como ya lo señalábamos, parta y termine por utilizar un lenguaje de interés, costo, peso y balance antes que de lo que es jurídico, antijurídico, correcto o incorrecto.

De hecho, para que la conmensurabilidad sea posible en el análisis de opciones alternativas en términos de costo-beneficio, es necesario que (1) los objetivos estén bien definidos, (2) los costos puedan ser comparados teniendo como parámetro una única unidad de valor o medida (peso o moneda, por ejemplo), (3) los beneficios también puedan ser cuantificados de un modo que puedan ser medidos unos a otros, y (4) las diferencias entre

\footnotetext{
${ }^{129}$ En Registro de usuarios en cibercafés (2011): Tribunal Constitucional de Chile, la sentencia estimó inaplicable el señalado registro sin acudir al test de proporcionalidad aunque se encontraban dos bienes en pugna (vida privada y combate contra la pornografía infantil). Los disidentes tampoco recurrieron al test para criticarla.

${ }^{130}$ En píldora del día después (2008): Tribunal Constitucional de Chile, hubo un disidente (Ministro Hernán Vodanovic) que habría aplicado el test de proporcionalidad. En la parte pertinente expresó: "el primer efecto del supuesto derecho es la obligación de la mujer de soportar el estado de embarazo, hipótesis que tampoco es absoluta, pues al colisionar derechos fundamentales, en este caso debe ponderarse la finalidad, medios utilizados e idoneidad de la protección de la vida por nacer; es decir, los medios empleados deben ser proporcionales al resto del ordenamiento constitucional, aptos y proporcionados a la entidad y relevancia de la vida por nacer y al ejercicio de los derechos de la mujer embarazada".

131 Píldora del día después (2008): Tribunal Constitucional de Chile.

132 Bordalí y ZúNiga (2010) p. 177, en que afirman que el principio de proporcionalidad "no es más que el reflejo de la relatividad de los derechos fundamentales, es decir, del hecho de que estos coexistan con otros intereses o bienes constitucionalmente protegidos con los que pueden entrar en conflicto", entre ellos, "el derecho a la vida del que está por nacer".

${ }^{133}$ ZúNiga (2010) p. 264 y, asimismo, en Bordalí y ZúNiga (2010) p. 177.

134 Webber (2010) p. 196.
} 
los medios, que no consistan en los costos y beneficios comparables, y otros aspectos como la eficiencia de los mismos medios, no se estimen de relevancia ${ }^{135}$.

El reparo anterior no supone el apoyo a una especie de inmovilismo jurisdiccional frente a las diversas o contrapuestas pretensiones en el ámbito jurídico-moral, sino que simplemente evidencia que el método del balanceo optimizador no es en sí mismo susceptible de tomar en consideración aspectos incalculables del bienestar humano bajo un estándar de análisis consecuencialista.

Sostener, con todo, que el referido test no posee la aptitud suficiente para servir de único o preferente parámetro de juicio en dichos eventos no supone desconocer el adecuado servicio que puede prestar en casos en que se encuentran en juego derechos que además de admitir legítimas restricciones por motivos de interés público -salvando siempre su núcleo esencial- gozan de un contenido primordialmente económico cuya naturaleza se aviene mejor con un método como el señalado.

Para ilustrar lo expuesto: creemos que es posible discutir, en clave de proporcionalidad, si una leve interferencia en la actividad de las empresas tabacaleras (libertad económica) se justifica con miras a promover la política pública de desincentivar el consumo de cigarrillo en la población (salud pública). En este caso, estamos frente a un derecho que admite limitaciones proporcionadas en pos de un fin público legítimo, impulsado por el gobierno, a condición de que no se impida su libre ejercicio (so pretexto de someterlo a regulación). Visto lo anterior, ¿puede aplicarse un razonamiento análogo cuando lo que se trata de regular es el uso de un símbolo o tradición religiosa que es obligatorio para sus fieles y que aparecería en colisión con el laicismo estatal sobre la materia o incluso con el interés contractual de preservar la "armonía estética" de un edificio de departamentos?

Esto último es lo que ocurrió en Syndicat Northcrest v. Amselem (2004) ${ }^{136}$, en que la Corte Suprema de Canadá se pronuncia sobre la demanda en que aparecen tensionados la libertad religiosa de creyentes judíos, que querían levantar en sus respectivos balcones una construcción transitoria de adoración (Succah), con el derecho de propiedad contractual representado por el reglamento de copropiedad que prohibía construcciones que comprometieran la "armonía estética" del edificio. El tribunal admitió la construcción de la "Succah" en el entendido que se encontraba estrechamente ligada con una práctica religiosa efectiva, con independencia de si ella era o no exigida por una autoridad religiosa.

¿En qué sentido la libertad de vestir el velo musulmán podría ser levemente restringida sin afectar la totalidad del derecho? Se observa así que las categorías conceptuales de restricción -leve, mediana y seria- típicas del estándar de proporcionalidad, no constituyen instrumentos adecuados para todos los casos de tensiones -aparentes o efectivas- entre derechos y/o bienes. Otro ejemplo en que se advierte la falencia señalada es que una injerencia, por muy minúscula que sea, al derecho a la vida, difícilmente puede ser equiparable (balanceable tampoco) siquiera con una leve infracción al derecho de propiedad.

$\mathrm{Al}$ estar en juego derechos fundamentales inviolables o con un contenido irreductible a un cálculo proporcionalista, su delimitación con otros derechos o bienes ha de proce-

${ }^{135}$ Finnis (1997) p. 219.

${ }^{136}$ En Syndicat Northcrest v. Amselem (2004). 
der por la vía de la argumentación y justificación, antes que por el expediente de medir lo inmedible, pues lo que hay tras el análisis de tensiones entre diversas pretensiones jurídicas es una ponderación acerca de las razones, ventajas o desventajas de alternativas disponibles y no un examen a llevarse a cabo bajo un parámetro preferente o excluyente de balanceo de intereses, costos, pesos o beneficios, que poco o nada dan cuenta de la naturaleza y envergadura de los bienes sujetos a evaluación, máxime cuando estos son inconmensurables ${ }^{137}$.

Todo lo expuesto precedentemente entrega elementos de juicio como para concluir que el test de proporcionalidad no sirve para todos los casos y mucho menos todavía para aquellos que exigen una adjudicación categórica de justicia ${ }^{138}$. Paralelamente, otras magistraturas lo han aplicado y desaplicado en casos similares y con idénticos resultados ${ }^{139}$, lo cual también siembra dudas en cuanto a su eventual inevitabilidad, incluso tratándose de casos en que no necesariamente se encuentran en juego derechos absolutos.

En fin y a modo de corolario, podemos señalar lo siguiente:

1. Que la versión más actualmente en boga del test proporcionalidad -atendida su estructura, finalidad y contexto histórico- contribuye a que los derechos queden en buena medida sujetos a un cálculo donde muchas veces prevalece la supuesta primacía de los objetivos estatales que legítimamente se pretenden alcanzar a costa del sacrificio de los derechos fundamentales. Con todo, hay una modalidad del aludido test que contiene las bases para una lectura no consecuencialista del mismo.

2. Una medida observada como proporcionada o justa conforme al test de proporcionalidad puede perfectamente hacer sucumbir los derechos fundamentales absolutos o aquellos aspectos inviolables de la mayoría de los derechos de las personas, con grave trasgresión a la prohibición de afectar el contenido esencial de los derechos o de imposibilitar su ejercicio so pretexto de intervención regulatoria.

3. Hay elementos como para sostener que la realidad desmiente o, al menos, pone en entredicho la supuesta vocación de universalidad del estándar en cuestión. Esto, sin perjuicio de reconocer la amplia aplicación de que este goza hoy en día en diversas latitudes. Con todo, debe destacarse positivamente que algunos tribunales que suelen emplearlo no lo han hecho en algunos casos en que han estimado que la dignidad humana o el contenido esencial de los derechos se encuentran en peligro.

4. Lo anterior, además de las consideraciones ya expuestas, dan para pensar seriamente que la proporcionalidad no sirve para todos los casos y derechamente no es pertinente para cierto tipo de controversias de adjudicación constitucional que exigen una categórica demanda de justicia.

\footnotetext{
137 WebBer (2010) pp. 194-197.

${ }^{138}$ Un buen ejemplo comparado de adjudicación categórica en que el tribunal se resiste a emplear el test de proporcionalidad por estimar que ello no conduciría a dicha respuesta, es Chahal v. United Kingdom (1996), en que la Corte Europea de DD.HH., reconociendo el tremendo desafío de las sociedades en repeler el terrorismo, rechaza utilizar la proporcionalidad toda vez que admite que ello podría debilitar la prohibición de la tortura a pesar de los alegatos en favor de la amenaza a la seguridad nacional, párr. 79 y 82.

139 En Solve et repete I (2008): Tribunal Constitucional de Chile, no se utilizó el test de proporcionalidad, en cambio sí se hizo en Solve et repete IV (2008) y V (2008) como también en la Sentencia de inconstitucionalidad del art. 171 del Código Sanitario (2009), casos del todo análogos.
} 


\section{BIBLIOGRAFÍA CITADA}

Alexy, Robert (1994): "Derechos individuales y bienes colectivos", El Concepto y la Validez del Derecho (Barcelona, Gedisa) 208 pp.

Alexy, Robert (2002): A Theory of Constitutional Rights (New York, Oxford University Press) 462 pp.

Alexy, Robert (2003): "On balancing and Subsumption. A Structural Comparison", Ratio Juris, vol. $16 \mathrm{~N}^{\circ} 4$, pp. 433-449.

Alexy, Robert (2010): “The Construction of Constitutional Rights", L. \& Etichs Human Rights, vol $4 \mathrm{~N}^{\circ} 1$, pp. 21-32.

Arancibia, Jaime (2011): Judicial review of commercial regulation (Oxford, Oxford University Press) $232 \mathrm{pp}$.

Barnes, Javier (1994): "Introducción al principio de proporcionalidad en el derecho comparado y comunitario", Revista de Administración Pública, vol. № 135, pp. 500-501.

BARnES, Javier (1998): "El principio de proporcionalidad. Estudio preliminar", Cuadernos de Derecho Público, vol. 5, pp. 15-49.

Bastress, Robert M. (1974): "Less Restrictive Alternative in Constitutional Adjudication: An Analysis, A Justification, and Some Criteria”, Vanderbilt Law Review, vol. 27 № 5 , pp. 971-1042.

BAstress, Robert M. (1998): "El principio de la 'alternativa menos restrictiva' en el Derecho constitucional norteamericano", Cuadernos de Derecho Público, vol. 5, pp. 239-244.

Beatty, David M. (2004): The Ultimate Rule of Law (New York, Oxford University Press) $92 \mathrm{pp}$.

Becaría, César (1982): De los delitos y de las penas (Madrid, Aguilar) 203 pp.

Bernal Pulido, Carlos (2003): El principio de proporcionalidad y los derechos fundamentales (Madrid, Centro de Estudios Políticos y Constitucionales) $871 \mathrm{pp}$.

Bertelsen Simonetti, Soledad (2010): Métodos de solución de conflictos entre derechos fundamentales, Cuadernos del Tribunal Constitucional, No 42, 108 pp.

Bidart Campos, Germán José (1984): La Corte Suprema. El Tribunal de las Garantías Constitucionales (Buenos Aires, Ediar) 107 pp.

Bordalí, Andrés y ZúNiga, Yanira (2010): "Análisis del fallo del Tribunal Constitucional sobre la píldora del día después”, Anuario de Derechos Humanos, Facultad de Derecho Universidad de Chile, pp. 173-182.

Brugger, Winfried (2000): "May Government Ever Use Torture? Two Responses from German Law", American Journal of Comparative Law, vol. 48, pp. 661-678.

Casinos Mora, Francisco Javier (2005): La presencia de los rasgos esenciales del principio de proporcionalidad en el pensamiento clásico y en el derecho romano (I), en AA.VV., Presente y Futuro de la Constitución Española de 1978, (Valencia, Tirant lo Blanch) pp. 185-204.

Cianciardo, Juan (2000): El conflictivismo en los derechos fundamentales (Pamplona, Eunsa) $424 \mathrm{pp}$.

Cianciardo, Juan (2007): El ejercicio regular de los derechos. Análisis y critica del conflictivismo (Buenos Aires, Ad-Hoc) 350 pp. 
Clerico, Laura (2010): "El examen de proporcionalidad: entre el exceso por acción y la insuficiencia por omisión o defecto”, en (Miguel Carbonell, Coord.) El principio de proporcionalidad en la interpretación jurídica, Cecoch (Santiago, Librotecnia), pp. 153-210.

Cohen-Eliya, Moshe y Porat, Iddo (2011): "Proportionality and the Culture of Justification", The American Journal of Comparative Law, vol. 59, pp. 463-490.

Conesa labastida, Luisa (2010): "La tropicalización del principio de proporcionalidad: la experiencia de Colombia y México en el ámbito de la igualdad”, Revista de Derecho Politico, UNED, vol. 77, pp. 351-377.

Covarrubias Cuevas, Ignacio (2011): "El bien común, el interés público o los fines constitucionalmente legítimos como justificaciones del regulador para limitar los derechos fundamentales", en (Arancibia, Martínez y Romero, coord.) Litigación Pública (Santiago, Abeledo Perrot-Thomson Reuters), pp. 397-433.

Craig, Paul P. (2003): Administrative Law (London, Sweet \& Maxwell) 1.045 pp.

Clayton, Richard y Tomlinson, Hugh (2000): The Law of Human Rights (Oxford, Oxford University Press) 298 pp.

De Búrca, Gráine (1993): “The Principle of Proportionality and its Application in EC Law”, Yearbook of European Law, vol. 13, pp. 105-150.

De la Riva, Ignacio (2004): Ayudas públicas. Incidencia de la intervención estatal en el funcionamiento del mercado (Buenos Aires, Hammurabi) 656 pp.

DíAz García, Iván L. (2011): "Aplicación del principio de proporcionalidad en orden a juzgar sobre la licitud o ilicitud de una restricción a derechos fundamentales", Revista de Derecho de la Pontificia Universidad Católica de Valparaíso, vol. 36, pp. 167-206.

Dworkin, Ronald (1985): A Matter of Principle (Cambridge Harvard University Press), $425 \mathrm{pp}$.

ElliotT, Mark (2001): "Scrutiny of Executive decisions under the Human Rights Act 1998: Exactly how 'Anxious'?”, Judicial Review, vol. 6 N³, pp. 166-176.

Emiliou, Nicholas (1996): The principle of proporcionality in european law: a comparative study (London, Kluwer Law International) 320 pp.

Fernández Nieto, Josefa (2009): La aplicación judicial europea del principio de proporcionalidad (Madrid, Dykinson) 324 pp.

FInNis, John (1997): "Commensuration and Public Reason”, en (Ruth Chang, ed.) Incommensurability, Incompatibility, and Practical Reason (Massachusetts, Harvard University Press), 384 pp.

Finnis, John (2000): Ley natural y derechos naturales (Buenos Aires, Abeledo Perrot) 455 pp.

Frantz, Laurent B. (1962): "The First Amendment is an Absolute", en Yale Law Journal, vol. 51, pp. 1424-1450.

García García, José Francisco (2011) "El tribunal constitucional y el uso de tests: Una metodología necesaria para fortalecer la revisión judicial económica”, Revista Chilena de Derecho, Vol. $38 \mathrm{~N}^{\circ}$ 1, pp. 101-138.

George, Robert P. (1989): "Individual Rights, Collective Interest, Public Law, and American Politics", Law and Philosophy, vol. 8, pp. 245-261.

Glendon, Mary Ann (2008): "Justice and Human Rights: Reflections on the Address of Pope Benedict to the UN", The European Journal of International Law, vol. $19 \mathrm{~N}^{\circ}$ 5, pp. 925-930. 
Grimm, Dieter (2007): "Proportionality in Canadian and German Constitutional Law Jurisprudence", University of Toronto Law Journal, vol. 57, pp. 383-395.

Hartwig, Matthias (2010): "La 'Proporcionalidad' en la Jurisprudencia del Tribunal Constitucional Federal de Alemania”, en Eduardo Ferrer Mac-Gregor y otros (Coord.) La justicia constitucional y su internacionalización ¿Hacia un ius constitucionale commune en América Latina?, Tomo I, México, pp. 781-791.

Isler Soto, Carlos (2011): "Una crítica Finnisiana al principio de proporcionalidad", en Ius Publicum, No 26, Escuela de Derecho Universidad Santo Tomás, Chile, pp. 31-52.

JellineK, George (2000): Teoría general del Estado (Granada, Comares) 788 pp.

Krauss, Ruprecht von (1955): Der Grunsatz Der Werhältnismässiegkeit in Seiner Bedeutung Für Die Notwendigkeit Des Mittels in Werfaltungsrecht (Hamburgo, Appel in Komm, Hamburgo) 25 pp.

Kumm, Mattias (2010): "The Idea of Socratic Contestation and the Right to Justification: The Point of Rights Based Proportionality Review”, Law \& Ethics Human Rights, vol. 4 $\mathrm{N}^{\circ}$ 1, pp. 142-175.

Lepsius Oliver (2006): "Human dignity and the downing of aircraft: the German Constitutional Court strikes down a prominent anti-terrorism provision in the New AirTransport Security Act”, German Law Journal, vol. 7 N 9, pp. 771-776

Lester, Anthony y Pannick, David (2004): Human Rights: Law and Practice (London, LexisNexis - Butterworths Law) 89 pp.

McCormick, Richard y Ramsey, Paul (1978): Doing Evil to Achieve Good. Moral Choice in Conflict Situations (Chicago, Illinois, Loyola University Press) pp. 7-53.

Martínez Estay, José Ignacio y Zúñiga Urbina, Francisco (2011): "El principio de razonabilidad en la jurisprudencia del Tribunal Constitucional”, Estudios Constitucionales, 9 $N^{\circ}$ 1, Centro Estudios Constitucionales de Chile, Universidad de Talca, pp. 199-226.

Martínez López-Muñiz, José Luis (1985): "Subvenciones al ejercicio de libertades y derechos fundamentales en el Estado social de Derecho: Educación y sindicatos", Revista Española de Derecho Administrativo, vol. 47, pp. 397-412.

Martínez Alarcón, María de la Luz (2008): "La aplicación judicial del derecho constitucional”, Teoría y realidad constitucional, UNED, vol. 21, pp. 355-374.

Martínez Zorrilla, David (2007): Conflictos constitucionales, ponderación e indeterminación normativa (Madrid, Marcial Pons) $392 \mathrm{p}$.

Medina Guerrero, Manuel (1997): La vinculación negativa del Legislador a los derechos fundamentales, (Madrid, Mc Graw Hill) 180 p.

Nogueira Alcalá, Humberto (2010): "El principio de proporcionalidad y su aplicación en Sudamérica por la Jurisdicción Constitucional, con especial mención al Tribunal Constitucional Chileno", en (Miguel Carbonell, Coord.) El principio de proporcionalidad en la interpretación jurídica, Cecoch (Santiago, Librotecnia) pp. 353-403.

Nogueira Alcalá, Humberto (2011): "El uso del postulado de proporcionalidad en la jurisprudencia de la Corte Interamericana de Derechos Humanos sobre libertad de expresión", Estudios Constitucionales, vol. 9, № 1, pp. 119-156.

Orrego SÁnchez, Cristóbal (2003): "La amenaza del consecuencialismo ético a los derechos humanos absolutos", Cuadernos Escuela de Derecho, Universidad Católica del Norte (Antofagasta) pp. 249-270 
Orrego Sánchez, Cristóbal (2010): "Supuestos conflictos de derechos humanos y la especifcación de la acción moral", Revista Chilena de Derecho, P. Universidad Católica de Chile, vol. $37 \mathrm{~N}^{\circ}$ 2, pp. 311-342.

Raz, Joseph (1986): The Morality of Freedom (Oxford Clarendon Press), 435 pp.

Rivers, Julian (2006): "Proportionality and variable intensity of review", Cambridge, Cambridge Law Journal, vol. $65 \mathrm{~N}^{\circ} 1$, pp. 174-207.

SAndel, Michael J. (1998): Liberalism and the limits of Justice, Cambridge University Press, Cambridge, $252 \mathrm{pp}$.

Sото Kloss, Eduardo (2009): “Acceso a las playas ¿un retorno al estatismo expoliador?”, Sentencias Destacadas 2009 (Santiago, Ediciones Libertad y Desarrollo) pp. 17-36.

Stender-Vorwachs, Jutta (2004): "The Decision of the Bundesverfassungsgericht of March 3, 2004 Concerning Acoustic Surveillance of Housing Space”, German Law Journal, vol. 5 No 11 , pp. 1.337-1.348.

Sullivan, Paul y Thomas F. Frase, Richard S. (2009): Proportionality Principles in American Law: Controlling Excessive Government Actions (Oxford, Oxford University Press), $284 \mathrm{pp}$.

Stone, Alec y Mathews, Jud (2009): "Proportionality balancing and global constitutionalism”, Columbia Journal of Transnational Law, vol. 47, pp. 73-163.

Prado, Maximiliano (2007): "Limitación de los derechos humanos: algunas consideraciones teóricas”, Revista Chilena de Derecho, vol. 34 No 1, pp. 61-90.

Prieto Sanchís, Luis (1990): Estudios sobre Derechos Fundamentales (Madrid, Ed. Debate) 267 pp.

Pereira Sáez, Carolina (2004): "Una contribución al estudio del empleo del principio de proporcionalidad en la jurisprudencia reciente del Tribunal Constitucional Español”, Anuario da Facultade de Dereito da Universidade da Coruña, vol. 8, pp. 1043-1062.

Perello Domenech, Isabel (1997): "El principio de proporcionalidad y la jurisprudencia constitucional”, Jueces para la Democracia, vol. 28, pp. 70 y ss.

Posner, Richard A. (1979): "Utilitarianism Economics, and Legal Theory", Journal of Legal Studies, vol. $8 \mathrm{~N}^{\circ} 1$, pp. 103-140.

SÁnchez GonzÁlez, Santiago (2003): "De la imponderable ponderación y otras artes del Tribunal Constitucional”, Teoría y realidad constitucional, UNED, vol. 12-13, pp. 351382.

Sullivan, Thomas F. y Frase, Richard S. (2009): Proportionality Principles in American Law (Oxford, Oxford University Press) 284 pp.

Thomas, Robert (2000): Legitimate Expectations and Proportionality in Administrative Law (Oxford, Hart Publishing) 129 pp.

Vivanco Martínez, Ángela (2009): "Negativa de un menor de edad y de su familia a que este reciba una terapia desproporcionada o con pocas garantías de efectividad", Revista Chilena de Derecho, vol. 36 No 2, pp. 399-440.

Wade, William y Forsyth, Christopher (2004): Administrative Law, (Oxford, Oxford University Press), 1.130 pp. 
Webber, Gregoire C. N. (2010): "Proportionality, balancing, and the cult of constitutional rights scholarship", Canadian Journal of Law and Jurisprudence, vol. 23, N 1, pp. 179202.

Würtenberger, Thomas (1999): “Der Schutz vom Eigentum und Freiheit im ausgehenden”, Walter Gose \& Thomas Würtenberger (editores) Zur Ideen-Und Rezeptionsgeschichte Des Presussisches Allgemeinen Landrecht Thomas Würtenberger, Der Schutz vom Eigentum und Freiheit im ausgehenden 18. Jahrhundert, $184 \mathrm{pp.}$

Zucca, Lorenzo (2011): "Los conflictos de derechos fundamentales como dilemas constitucionales", en (AAVV) Dilemas Constitucionales (Madrid, Marcial Pons) 132 pp.

Zúñıga AÑAZco, Yanira (2010): "El principio de proporcionalidad como herramienta de racionalidad. Un análisis crítico de su aplicación en la jurisprudencia del tribunal constitucional chileno", Ius et Praxis, vol. 16, No 2, pp. 249-272.

\section{JURISPRUDENCIA CITADA}

A. v. Secretary of State for the Home Department (2005): Privy Council, House of Lords, 8 de diciembre de 2005 (apelación).

Ashingdane v. United Kingdom (1985): Corte Europea de Derechos Humanos, 28 de mayo de 1985 (apelación).

Begoña Sánchez Espinosa v. Dirección General de Seguridad Ciudadana de Barcelona (2009): Tribunal Constitucional de España, de 9 de febrero de 2009 (amparo).

Chahal v. United Kingdom (1996): Corte Europea de Derechos Humanos, 15 de noviembre de 1996 (apelación).

De Freitas v. Permanent Secretary of Ministry of Agriculture, Fisheries, Land and Housing (1999): Privy Council, House of Lords, 30 de junio de 1998 (apelación).

Decreto de Urbanismo y Construcción (2003): Tribunal Constitucional de Chile, 9 de abril de 2003 (inaplicabilidad).

Dunn v. Blumstein (1972): Tribunal Supremo Norteamericano, 21 de marzo de 1972 (certiorari).

Geouffre de la Pradelle v. France (1992): Corte Europea de Derechos Humanos, 16 de diciembre de 1992 (apelación).

Germany v. Council (1994): Corte Europea de Derechos Humanos, 5 de octubre de 1994 (apelación).

Griswold, v. Connecticut (1965): Tribunal Supremo Norteamericano, 7 de junio de 1965 (certiorari).

Hauer v. Land Rheinland-Pfalz (1979): Corte Europea de Justicia, 13 de diciembre del 2009 (cuestión prejudicial).

Inconstitucionalidad normas de aborto Código Penal de Colombia (2006): Corte Constitucional de Colombia, 10 de mayo del 2006 (acción de inconstitucionalidad).

Lawton v. Steele (1894): Tribunal Supremo Norteamericano, 5 de marzo de 1894 (certiorari).

Ley de Concesiones (2006): Tribunal Constitucional de Chile, 17 de noviembre de 2006 (inaplicabilidad). 
Matthews v. United Kingdom (1999): Corte Europea de Derechos Humanos, 18 de febrero de 1999 (apelación).

Mathieu-Mohin v. Belgium (1987): Corte Europea de Derechos Humanos, 2 de marzo de 1987 (apelación).

Pildora del día después (2008): Tribunal Constitucional de Chile, 18 de abril de 2008 (inaplicabilidad).

Playas II (2009): Tribunal Constitucional de Chile, 17 de marzo de 2009 (inaplicabilidad).

Registro de usuarios en cibercafés (2011): Tribunal Constitucional de Chile, 12 de julio de 2011 (inaplicabilidad).

R. (Daly) v. Secretary of State for the Home Department (2001): Privy Council, House of Lords, 23 de mayo de 2001 (apelación).

Regina v. Oakes (1986): Corte Suprema de Canadá, 28 de febrero de 1986 (apelación).

Reclamo de constitucionalidad de la Ley antiterrorista alemana (2006): Tribunal Federal Constitucional Alemán, 15 de febrero del 2006 (requerimiento de control preventivo de constitucionalidad).

Reclamo de constitucionalidad de la Ley de escuchas en hogares (2004): Tribunal Federal Constitucional Alemán, 03 de marzo del 2004 (requerimiento de control preventivo de constitucionalidad).

Philis v. Greece (1997): Corte Europea de Derechos Humanos, 27 de Junio de 1997 (apelación). Rees v. United Kingdom (1986): Corte Europea de Derechos Humanos, 16 de octubre de 1986.

Selim Sadak v. Turkey (2002): Corte Europea de Derechos Humanos, 11 de junio del 2002. Solve et repete I (2008): Tribunal Constitucional de Chile, 3 de enero de 2008 (inaplicabilidad).

Solve et repete IV (2008): Tribunal Constitucional de Chile, 22 de julio de 2008 (inaplicabilidad).

Solve et repete $V$ (2008): Tribunal Constitucional de Chile, 28 de agosto de 2008 (inaplicabilidad).

Solve et repete (2009): Tribunal Constitucional de Chile 25 de mayo de 2009 (inconstitucionalidad del art. 171 del Código Sanitario).

Suresch v. Canada (2002): Corte Suprema de Canadá, 11 de enero del 2002 (apelación).

Syndicat Northcrest v. Amselem (2004): Corte Suprema de Canadá, 30 de junio del 2004 (apelación).

Turno gratuito (2007): Tribunal Constitucional de Chile, 31 de marzo de 2007 (inaplicabilidad).

TVN con Consejo para la Transparencia (2011): Tribunal Constitucional de Chile, 21 de julio de 2011 (inaplicabilidad).

United States v. Robel (1967): Tribunal Supremo Norteamericano, 11 de diciembre de 1967 (certiorari).

Zdanoka v. Latvia (2006): Corte Europea de Derechos Humanos, 16 de marzo del 2006 (apelación). 